\title{
CONTRIBUIÇÃO AO ESTUDO DA FAMÍLIA SPELAEORHYNCHIDAE OUDEMANS, 1902 (ACARINA, MESOSTIGMATA)
}

\author{
Adriano Lucio Peracchi ${ }^{1}$
}

\begin{abstract}
Contribution to the study of the family Spelaeorhynchidae Oudemans, 1902 (Acarina: Mesostigmata) - A revision of the family Spelaeorhynchidae Oudemans, 1902 with descriptions of three new species from Brazil, Peru and Colombia.
\end{abstract}

Key words: Spelaeorhynchus - Spelaeorhynchidae - bat parasites.

\section{INTRODUÇÃO}

Os acarinos da família Spelaeorhynchidae são ectoparasitos de quirópteros neotropicais, sendo encontrados firmemente fixados, através de robustas quelíceras, aos técidos dos hospedeiros.

Os Spelaeorhynchidae adultos lembram um pequeno ixodídeo e quando não diafanizados, apresentam gnatossoma e patas castanhas, idiossoma esbranquiçado, com exœção dos escudos dorsal e ventral que são de coloração castanha.

$\mathrm{O}$ seu ciclo evolutivo é ainda obscuro. As fêmeas são vivíparas e os machos não são conhecidos e provavelmente são de vida livre, habitando os refúgios dos morcegos.

NEUMANN (1902) ao estudar a coleção de Ixodidae do Museu de Berlim encontrou quatro exemplares de um interessante acarino que descreveu como Spelaeorhynchus praecursor, gênero novo, espécie nova. Esses exemplares estavam em mistura com uma fêmea de Hyalomma aegyptium (L.), num frasco com a seguinte indicação "sem pátria". Por essa razão, aquele autor supôs, com alguma reserva, que os seus exemplares eram africanos e parasitos do boi. Contudo, sem deçidir taxativamente sobre a posição sistemática do novo gênero, chamou a atenção para o fato de que a sua nova espécie se distinguia claramente não só dos Ixodidae, mas também, dos outros grupos, representando um tipo que poderia servir de base à criação de uma familia ou subfamíla distintas.

OUDEMANS (1902) na Revisão Estival da Sociedade Entomológica Neerlandesa apresenta uma classificação dos acarinos, na qual comenta o parentesco entre os Parasitidae (Gamasidae), Ixodidae e Spelaeorhynchidae, criando assim uma família para receber a única espécie conhecida. Além do mais, reúne essas famílias no grupo dos Mesostigmata pela posição dos estigmas respiratórios e chama a atenção para a posição da vulva nos Spelaeorhynchidae. 
NEUMANN (1902) encontra na coleção do Museu Britânico mais um exemplar de $S$. praecursor, com o seguinte rótulo: "From Carollia brevicauda. Pernambuco. J.F.G. Smith Esq.". Essa indicação esclareceu que $S$. praecursor era uma espé cie neotropical e que seu hospedeiro era um quiróptero.

BANKS (1915) na sua Revião dos Acarinos, ao tratar da familia Spelaeorhynchidae, assinala a ocorrência de outra espécie em quirópteros do Panamá, sem contudo descrevê-la. Posteriormente, BANKS (1917) descreve Spelaeorhynchus latus, espécie nova, com base em material colecionado sobre morcego não determinado, na região de Obispo, Zona do Canal, Panamá. Nessa ocasião considerou o gênero aproximado tanto dos Parasitidae como dos Ixodidae, colocando-o entre os Parasitoidea, baseado na placa esternal, posição da abertura genital e mandibulas retráteis e, também, porque a extremidade anterior era muito diferente do capítulo dos Ixodidae.

FONSECA (1935) ao estudar 8 exemplares de Spelaeorhynchus colecionados sobre Glossophaga soricina, Lonchoglossa ecaudata e Hemiderma perspicillata procedentes dos Estados de São Paulo, Rio de Janeiro e Minas Gerais, respectivamente, considera-os como $S$. latus apesar de não concordarem inteiramente com a descrição de BANKS (1917) e considera aberta a questão sobre a validade das duas espécies ao afirmar que a mesma só poderá ser resolvida definitivamente pela redescrição ou comparação dos exemplares-tipo.

FOX (1942) assinala pela primeira vez a ocorrência do gênero Spelaeorhynchus em Porto Rico, com base em cinco exemplares colecionados sobre Artibeus jamaicensis jamaicensis Leach.

RADFORD (1950) cita o gênero Spelaeorhynchus como monotípico, reconhecendo, implicitamente, $S$. latus como sinônimo de $S$. praecursor.

VIGUERAS (1956) assinala a ocorrência de $S$. praecursor sobre Artibeus jamaicensis parvipes colecionado em Cuba.

FONSECA (1958) estudando a área sensorial do tarso I de Spelaeorhynchus latus conclui que essa estrutura é um órgão de Haller bem desenvolvido e considera a espécie como um Ixodidae primitivo.

DIAS (1958) ao estudar os ixodideos do Museu de Hamburgo descreve Spelaeorhynchus cubanus, espécie nova, com base em seis exemplares colecionados em Cuba, sobre hospedeiros desconhecidos

ARAGÃO \& FONSECA (1961) consideram os Spelaeorhynchidae como integrantes da subordem Ixodides e $S$. latus como sinónimo de $S$. praecursor.

TABOADA (1965) ao apresentar lista dos parasitos de morcegos cubanos assinala a ocorrência de $S$. praecursor, com base na observação de VIGUERAS (loc. cit.) e de $S$. latus tendo em vista a existência de um exemplar dessa espécie, depositada na coleção do United States National Museum, colecionado sobre Artibeus jamaicensis parvipes.

MACHADO-ALLISON (1967) tece comentários sobre os conhecimentos existentes a respeito de alguns ectoparasitos de mamais da biota amazonica e ao abordar a familia Spelaeorhynchidae afirma ser ainda confuso o status das duas espécies, $S$. praecursor e $S$. latus. Assinala ainda a coleta de numerosos exemplares de Spelaeorhynchus em diversas localidades da Venezuela e ao sul do Orenoco.

FAIN et al. (1967) concluem que o gênero Spelaeorhynchus não concorda perfeitamente nem com os Mesostigmata nem com os Ixodides, mas que, indubitavelmente, é muito mais aproximado da primeira. Nesse mesmo trabalho descrevem $S$. monophylli e $S$. chilonycteris, espécies novas, a primeıra parasita de Monophyllus portoricensis, co- 
letado em Porto Rico, e a segunda de Chilonycteris rubiginosa rubiginosa, colecionada na Guatemala. Por outro lado, baseados em numerosos exemplares colecionados sobre Artibeus jamaicensis de Porto Rico, República Dominicana e Cuba, e comparando esse material com um cotipo de $S$. latus, concluem ser essa espécie um sinônimo de $S$. praecursor. Esses autores tiveram também a oportunidade de examinar dois exemplares, colecionados em Pernambuco, Brasil, sobre Carollia brevicauda, um deles pertencente ao Museu Britânico e que foi estudado por Neumann em 1906, que foram determinados como Spelaeorhynchus sp. por não concordarem inteiramente com os exemplares capturados sobre Artibeus jamaicensis jamaicensis procedentes das Antilhas.

DUSBÁBEK (1970 a) apresenta alguns dados sobre acarinos parasitos de mamais capturados em Cuba è no México e ao tratar de $S$. praecursor assinala a sua presença naquela ilha, sobre Artibeus jamaicensis e admite possibilidade de $S$. cubanus Dias, ser sinônimo daquela espécie.

DUSBÁBEK (1970 b) examinando os parátipos de $S$. cubanus conclui pela sinonimia da mesma com $S$. praecursor e apresenta a descrição de uma ninfa dessa espécie.

TAMSITT \& FOX (1970) apresentam dados sobre ectoparasitos de quirópteros colecionados na Colômbia, Guiana, Porto Rico e Jamaica, e ao tratarem dos Spelaeorhynchidae assinalam a ocorrência de S. praecursor sobre Carollia perspicillata na Colômbia e Artibeus jamaicensis jamaicensis em Porto Rico, bem como de S. monophylli sobre Monophyllys redmani portoricensis em Porto Rico.

TAMSITT \& VALDIVIESO (1970) apresentam observações sobre morcegos e seus ectoparasitos realizadas em Porto Rico e assinalam a presença de $S$. monophylli sobre Monophyllus redmani.

\section{MATERIAL E MÉTODOS}

\section{Material}

Ao iniciarmos o estudo dos Spelaeorhynchidae dispúnhamos somente dos exemplares colecionados no decorrer de nossos trabalhos sobre os quirópteros do sudeste brasileiro. Posteriormente tivemos a oportunidade de receber interessante material colecionado em Xavantina, Mato Grosso, bem como de examinar os exemplares depositados nas coleções da Escola Paulista de Medicina e da Seção de Parasitologia do Instituto Butantan, estes últimos estudados por Flávio da Fonseca. Apesar do estado precário em que se encontra o material estudado por Fonseca em virtude da deterioração parcial do meio de montagem, foi possível observar os principais caracteres necessários para sua determinação. Finalmente, foi possível estudar valioso material depositado nas colecões do Field Museum of Natural History, Chicago, e Brigham Young University, Utah, EUA, colecionado sobre quirópteros do Peru, Colômbia, Venezuela, Guatemala, Honduras Britânicas, México e Jamaica.

As seguintes abreviações serão usadas para identificar as coleções onde os espécimes se encontram depositados:

BY - Brigham Young University, Utah, EUA.

EM - Escola Paulista de Medicina, São Paulo.

FM - Field Museum of Natural History, Chicago, EUA.

IB - Seção de Parasitologia, Instituto Butantan, São Paulo.

UR - Área de Zoologia, Instituto de Biologia, Universidade Federal Rural do Rio de Janeiro. 


\section{Métodos}

Com exceção de 11 fêmeas depositadas na coleção do Instituto Butantan, que já estavam montadas em lâminas, todo o material que utilizamos no decorrer de nossos estudos estava conservado em álcool $70^{\circ} \mathrm{GL}$.

Tendo em vista a necessidade de serem clarificados os exemplares para estudo, a consistência da cutícula dos Spelaeorhynchidae e a dificuldade para destruir o conteúdo dos cecos intestinais desses acarinos, tomou-se indispensável testar vários agentes clarificadores. Os melhores resultados foram obtidos com o emprego de solução de $\mathrm{KOH}$ a $1 \%$. Nesse caso o material foi colocado na solução, em pequenos frascos com tampa e submetidos à temperatura de $45^{\circ} \mathrm{C}$, em estufa. Freqüentemente, depois de 48 horas, o conteúdo dos cecos já havia sido destruído, sendo então os exemplares retirados e lavados em água. A seguir completava-se a clarificação no líquido de Vitzthum(ZUMPT et al., 1961), obtendo-se, geralmente, ao fim de 48 horas de tratamento na estufa a $45^{\circ} \mathrm{C}$, exemplares perfeitamente transparentes. Os exemplares clarificados foram montados entre lâmina e lamínula, em líquido de André (SINGER, 1967) e submetidos durante 5 dias à temperatura de $50^{\circ} \mathrm{C}$, em estufa. Finalmente, procedeu-se à lutagem das preparações com esmalte de unhas incolor, visando retardar a alteração das mesmas.

Algumas fêmeas grávidas foram dissecadas para possibilitar a retirada das respectivas larvas. Essa operação foi realizada com o auxilio de microscópio estereoscópico, após a clarificação do material. Cada fêmea era colocada numa lâmina, com pequena quantidade de líquido de André e com o auxilio de 2 estiletes de ponta fina rompiamos a parede lateral do opistossoma, libertando a larva.

Os desenhos foram realizados através de câmara clara montada em microscópio de contraste de fase WILD M-20 e as medidas foram obtidas com ocular micrométrica de mesma fabricação.

\section{RESULTADOS}

Acarina Nitzsch, 1818

Mesostigmata Canestrini, 1819

Spelaeorhynchidae Oudemaris, 1902

Spelaeorhynchidae Oudemans, 1902:55; Banks, 1915:70; Vitzthum, 1931:

18, 40; Lombardini, 1938:210; Vitzthum, 1940:55-56; Vitzthum,

1942:774; Baker \& Wharton, 1952:61; Baker, Camin, Cunliffe, Wooley

\& Yunker, 1958:32; Krantz, 1970:112

Spelaeorhynchinae Neumann, 1911:134.

Spelaeorhynchoidea Ewing, 1934:64.

A família Spelaeorhynchidae compreende um único gênero, Spelaeorhynchus, com várias espécies, todas parasitas de quirópteros neotropicais.

Caracteres do gênero Spelaeorhynchus Neumann, 1902:

Fêmea adulta: corpo sub-circular, um tanto achatado e com a maior largura no opistossoma.

Gnatossoma: livre, em forma de túnel fortemente esclerosado (camerostômio), 'parcialmente dividido por 2 projeções internas, formado pela fusão das coxas dos palpos com o hipostômio. Esse túnel abriga as quelíceras e apresenta próximo à abertura, uma fran- 
Vol. 7(1-2), 1990

ja interna de pequenas estruturas setiformes, ausente somente na face ventral. A superfície dorsal do gnatossoma pode ser lisa ou esculturada e a ventral apresenta 3 pares de pequenos espinhos. Quelíceras robustas, terminando por 2 dígitos providos de dentes fortes Palpos curtos, inseridos lateralmente, de 5 artículos dotados de espessamentos laterais internos, apresentando cerdas conspícuas. Trocanter sub-quadrado, ventralmente com expansão membranosa apical que recobre parcialmente o fêmur, impedindo o seu movimento para baixo; dotado de 2 cerdas, a maior, lateral, no ângulo superior interno e a menor, ventral, basal e sub-lateral extema. Fêmur ligeiramente mais longo que largo, com 5 cerdas: 2 laterais (a maior implantada no ângulo superior interno e a menor no ângulo superior externo) e 3 dorsais (a maior, mediana e as menores, iguais, sendo 1 sublateral externa, na metade basal do segmento e a outra, sub-lateral, próxima ao*ângulo superior interno). Joelho mais longo que largo, com 4 cerdas: 2 laterais (a maior, inserida no ângulo superior intemo e a menor, no ângulo superior externo) e 2 dorsais (a maior, mediana e a menor, sub-lateral, próxima ao ângulo superior interno). Tíbia subcilíndrica, com 8 cerdas: 2 ventrais (iguais, implantadas sub-lateralmente, no terço apical), 2 laterais (iguais, no terço apical) e 4 dorsais (sendo 2 curtas, sub-laterais, no terço mediano e 2 apicais, longas e cilíndricas). Tarso sub-cilindrico, com 7 cerdas: a mais longa, ventral e mediana, 3 apicais e 3 menores, dorsais.

Idiossoma: revestido por cutícula finamente estriada, apresentando escudos dorsal e esternal situados próximo ao gnatossoma. Escudo dorsal mais longo que largo, levemente esclerosado, dotado de 4 pares de poros glandulares, sendo 1 par lateral e 3 pares medianos dispostos em 2 filas longitudinais. Escudo esternal de forma variável, fortemente esclerosado, guarnecido de 2 pares de poros glandulares, o primeiro na margem anterior e o segundo nas margens laterais. Peritremas elípticos, situados lateralmente, ao nível da coxa IV. Espiráculo localizado na metade posterior do peritrema. O escudo genital desapareceu totalmente e o anal sofreu grande redução estando representado por 3 pequeninas placas, levemente esclerosadas, que circundam a base das 3 verdas anais. Aberturas genital e anal ventrais e sub-terminais, a primeira em forma de estreita fenda transversal, situada pouco antes da segunda. Abertura anal arredondada dotada de fenda longitudinal, situada próximo à extremidade posterior. Para trás da abertura anal existe pequena área provida de diminutos espinhos. O idiossoma é provido de cerdas conspícuas, que obedecem quetotaxia definida, ocorrendo: cerdas póstero-laterais - em número variável, situadas nas bordas laterais e posteriores do opistossoma; cerdas dorso-laterais - em número de 3 a 5 pares situados dorsalmente nas bordas do podossoma, sendo que os dois últimos estão ao nível do peritrema e os demais à sua frente; cerdas pósterodorsais - em número de 2 a 3 pares, medianos, situados dorsalmente, próximo ao ápice do opistossoma; cerdas escutais - 1 par situado dorsalmente, nos ângulos anteriores do escudo dorsal; cerdas peri-escutais - 6 a 7 pares situados junto às margens do escudo dorsal, havendo sempre um par anterior, inserido no espaço existente entre o escudo e o gnatossoma; cerdas esternais - 1 par implantado lateralmente, junto aos poros glandulares laterais; cerdas peri-esternais - 2 pares, sendo um anterior, implantado em frente ao escudo e um lateral, inserido para trás das cerdas esternais; cerdas ventro-laterais - em número variável, situadas na face ventral do opistossoma, de cada lado da linha mediana. As mais posteriores estão ao nível da abertura genital e freqüentemente se confundem com as cerdas póstero-laterais; cerdas genitais -1 par ladeando a abertura genital; cerdas anais - em número de 3 , sendo 2 laterais à abertura anal e a terceira posterior à referida abertura Todas as cerdas, com exceção das póstero-laterais, são pectinadas em sua metade apical. Patas de 6 artículos, todos com conspicuos espessamentos laterais internos, 
guarnecidos de cerdas dorsais mais longas que as ventrais e as laterais. Coxas parcialmente embutidas no podossoma, dotadas de pequeno processo dentiforme no meio do bordo apical; as do primeiro par sub-triangulares, as demais sub-retangulares. Trocanteres sub-quadrados, os das patas I e II articulando-se com a face dorsal das respectivas coxas, permitindo somente movimentos para cima. Fêmures sub-cilíndricos, divididos - em basifêmur e telofêmur, o primeiro sub-quadrado e glabro, o segundo sub-cilíndrico. Joelhos e tíbias sub-cilíndricas. Tarso I sub-cilíndrico, com ápice arredondado, tarsos II, III e IV divididos em basitarso e telotarso, sub-cônicos, com ápice acuminado. Tarso I apresentando dorsalmente, próximo ao ápice, área sensorial representada por pequena depressão arredondada, com bordos laterais e basal ligeiramente espessados e provida de 4 solenídias bem desenvolvidas, de ápice truncado e 3 diminutas cerdas espiniformes. Ambulacros caducos.

Larva (obtida por dissecação de fêmeas grávidas): corpo oval, recoberto por cuticula verrucosa, dotado de patas robustas.

Gnatossoma: quelíceras sub-cônicas. com dígitos curtos. Palpos bem desenvolvidos, com artículos mais largos que longos, providos de cerdas conspícuas (exceto o trocanter que é glabro). Fêmur com 5 œrdas, joelho com 4, tíbia com 8 e tarso com 6 . Ventralmente 1 par de pequeninas cerdas situadas próximo à margem anterior e 2 pares de cerdas maiores, sub-medianas. Dorsalmente com 1 par de cerdas sub-medianas.

Idiossoma: com 16 pares de cerdas dorsais: 4 pares laterais, situados próximo às bordas do podossoma, 3 posteriores nas margens do opistossoma e os demais em 2 filas longitudinais de cada lado do meio do idiossoma. Ventralmente com 10 pares de cerdas: 6 em fila longitudinal sub-mediana e 4 nas margens do opistossoma. Tritosterno conspícuo. Patas bem desenvolvidas com ambulacros dotados de 2 unhas fortes e recurvas.

\section{Chave para determinação das espécies do gênero Spelaeorhynchus}

1 - Escuro esternal reticulado; face dorsal do gnatossoma ornada com 8 linhas longitudinais . . . . . . . . S. chilonycteris Fain, Anastos, Camin \& Johnston, 1967. Escudo esternal sem omamentação; face dorsal do gnatossoma lisa ou reticulada. 2

2 - Face dorsal do gnatossoma lisa; palpos sem cerdas espatuladas . . . . . S. jimi n. sp. Face dorsal do gnatossoma reticulada; palpos com cerdas espatuladas . . . . . . 3

3 - Escudo esternal sub-triangular, uniformemente esclerosado . . . . . . . . . . . 4 Escudo esternal com estreita faixa transversal anterior, distintamente mais esclerosada que o restante . . . . . . . . . . . . . . . . 5

4 - Escudo esternal envolvido lateralmente por área de cutícula nitidamente esclerosada . . . . . . . . . S. monophylli Fain, Anastos, Camin \& Johnston, 1967. Somente o escudo esternal esclerosado . . . . . . . S. praecursor Neumann, 1902.

5 - Área menos esclerosada do escudo esternal sub-triangular; escudo dorsal com nítida reentrân cia lateral no terço anterior . . . . . . . . . soaresi n. sp. Área menos esclerosada do escudo esternal semicircular; escudo dorsal com margens laterais convexas no terço anterior . . . . . . . . wenzeli n. sp. 
Vol. 7(1-2), 1990

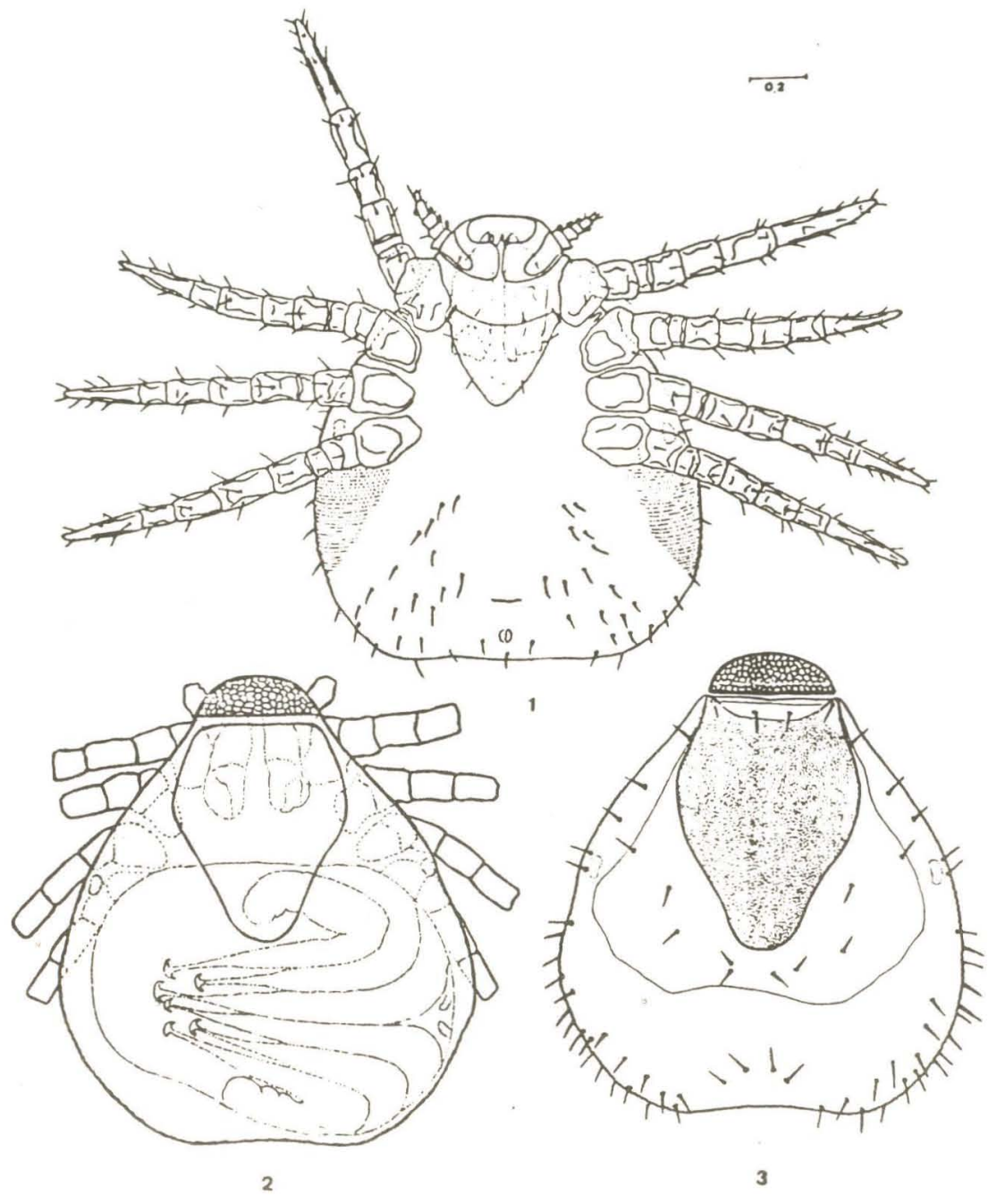

Spelaeorhynchus praecursor Neumann - Fêmea adulta: Fig. 1 - Vista ventral; Fig. 2 - Fêmea grávida com larva; Fig. 3 - Vista dorsal. Escalas em mm. 


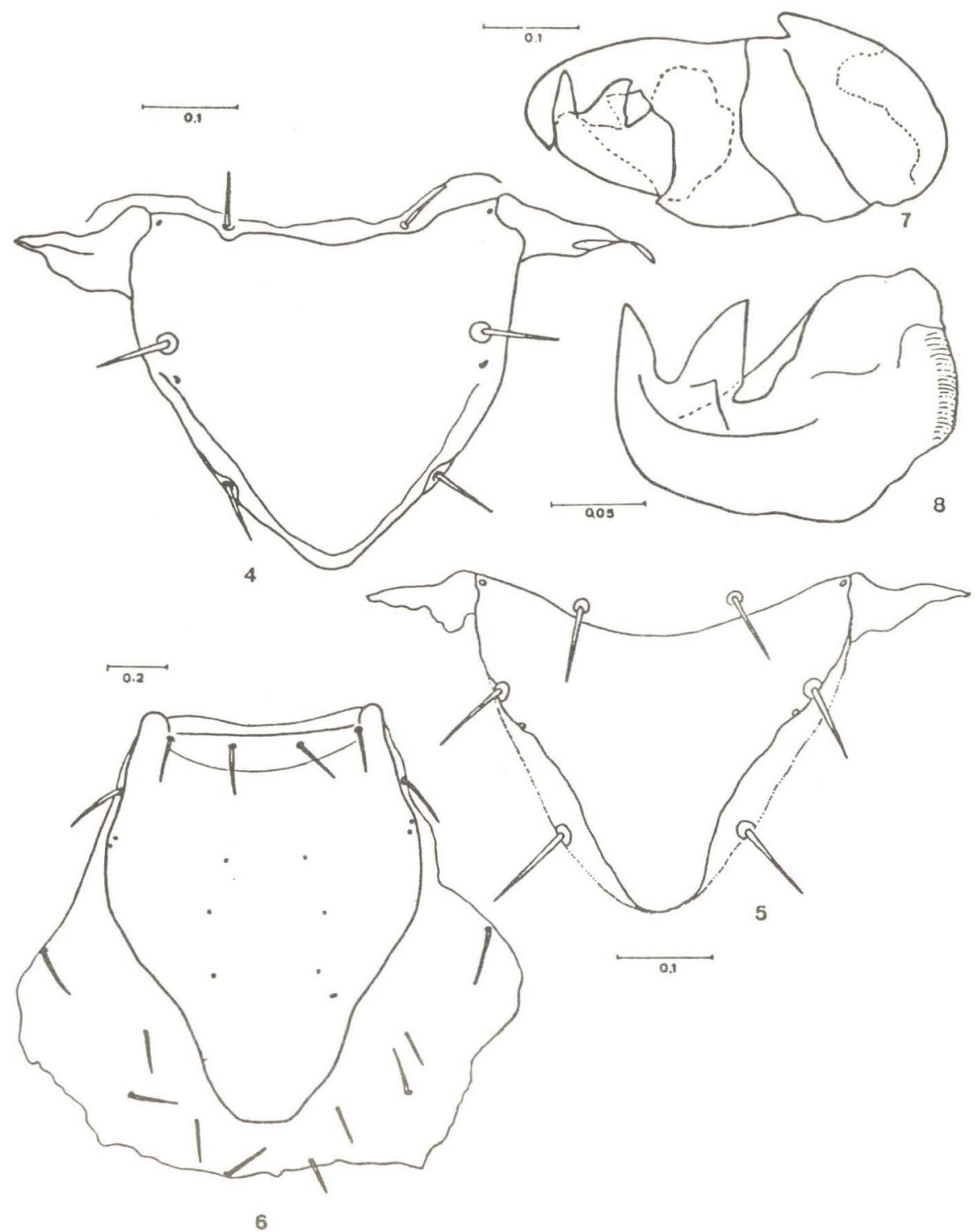

Spelaeorhynchus praecursor Neumann - Fêmea adulta:Fig. 4 - Escudo esternal; Fig. 5 - Escudo esternal; Fig. 6 - Escudo dorsal; Fig. 7 - Quelícera;Fig. 8 - Dígito móvel. Escalas em mm. 
Vol. 7(1-2), 1990

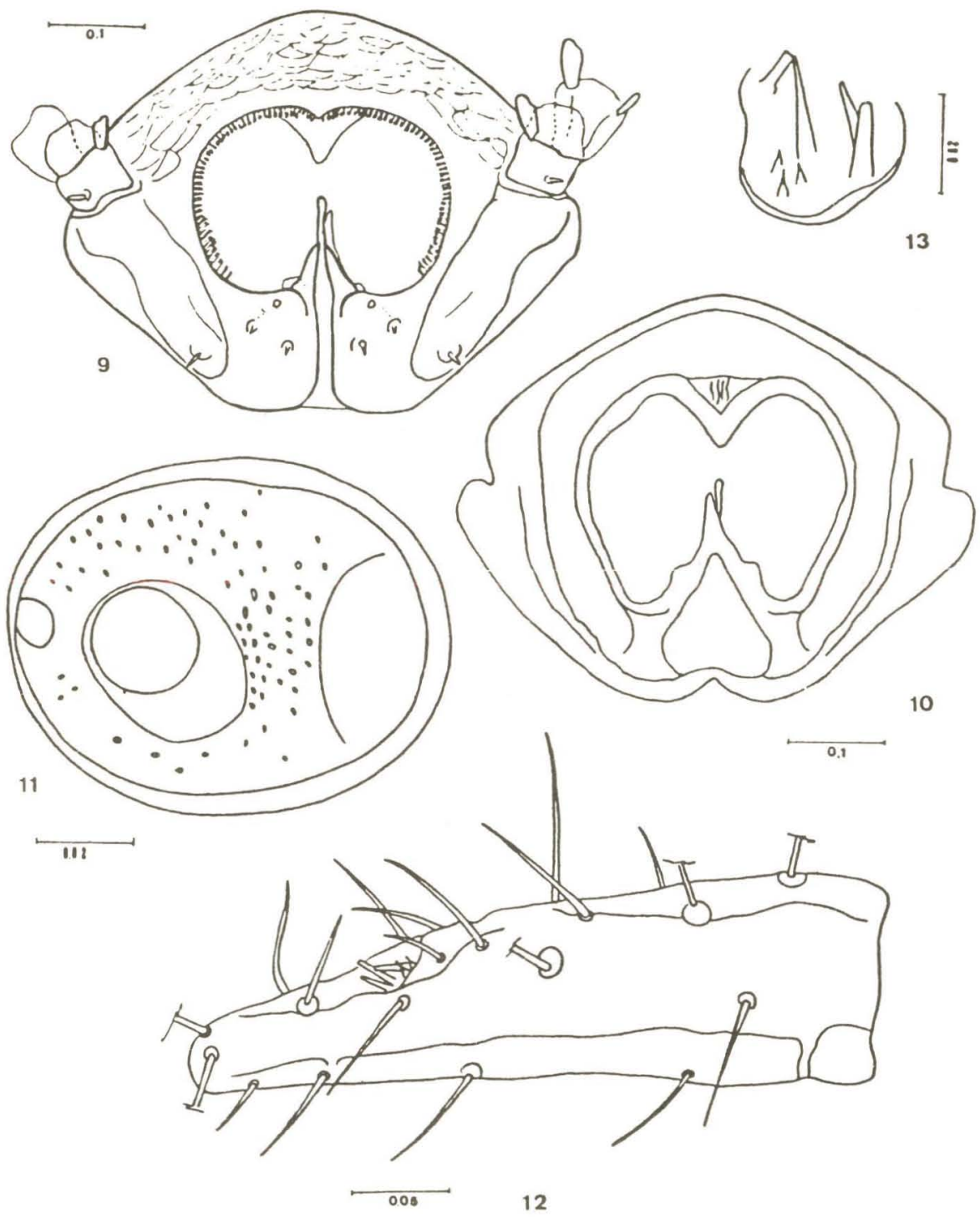

Spelaeorhynchus praecursor Neumann - Fêmea adulta: Fig. 9 - Gnatossoma - visto de frente; Fig. 10 - Gnatossoma - visto por trás; Fig. 11 - Peritrema; Fig. 12 - Vista lateral do tarso I; Fig. 13 - Área sensorial do tarso I. Escalas em mm. 
Revta bras. Zool.
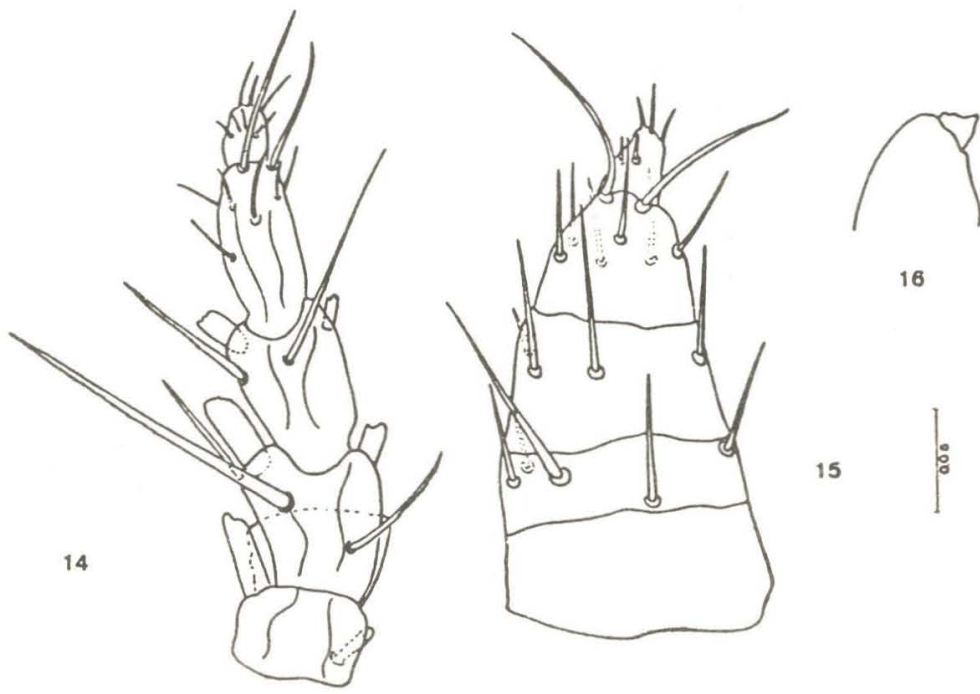

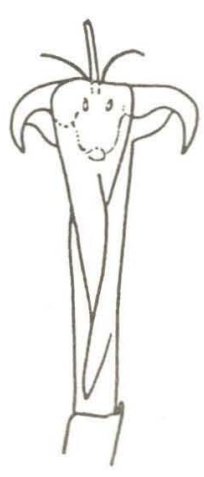

17

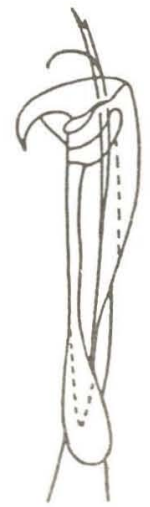

18

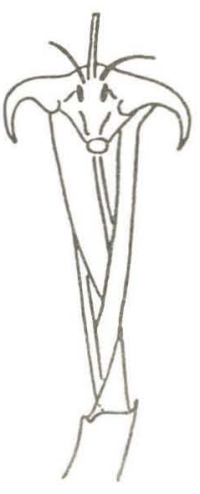

19

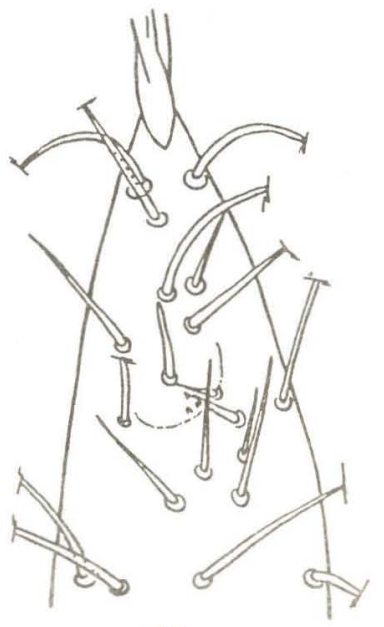

20

Spelaeorhynchus praecursor Neumann: Fig. 14 - Fêmea adulta: Vista dorsal do palpo; Fig. 15 Larva: Vista dorsal do palpo; Fig. 16 - Larva: Quelícera; Figs. 17 a 19 - Larva: Carúncula tarsal; Fig. 20 - Larva: Vista dorsal da extremidade do tarso I. Escalas em mm. 
Vol. $7(1-2), 1990$
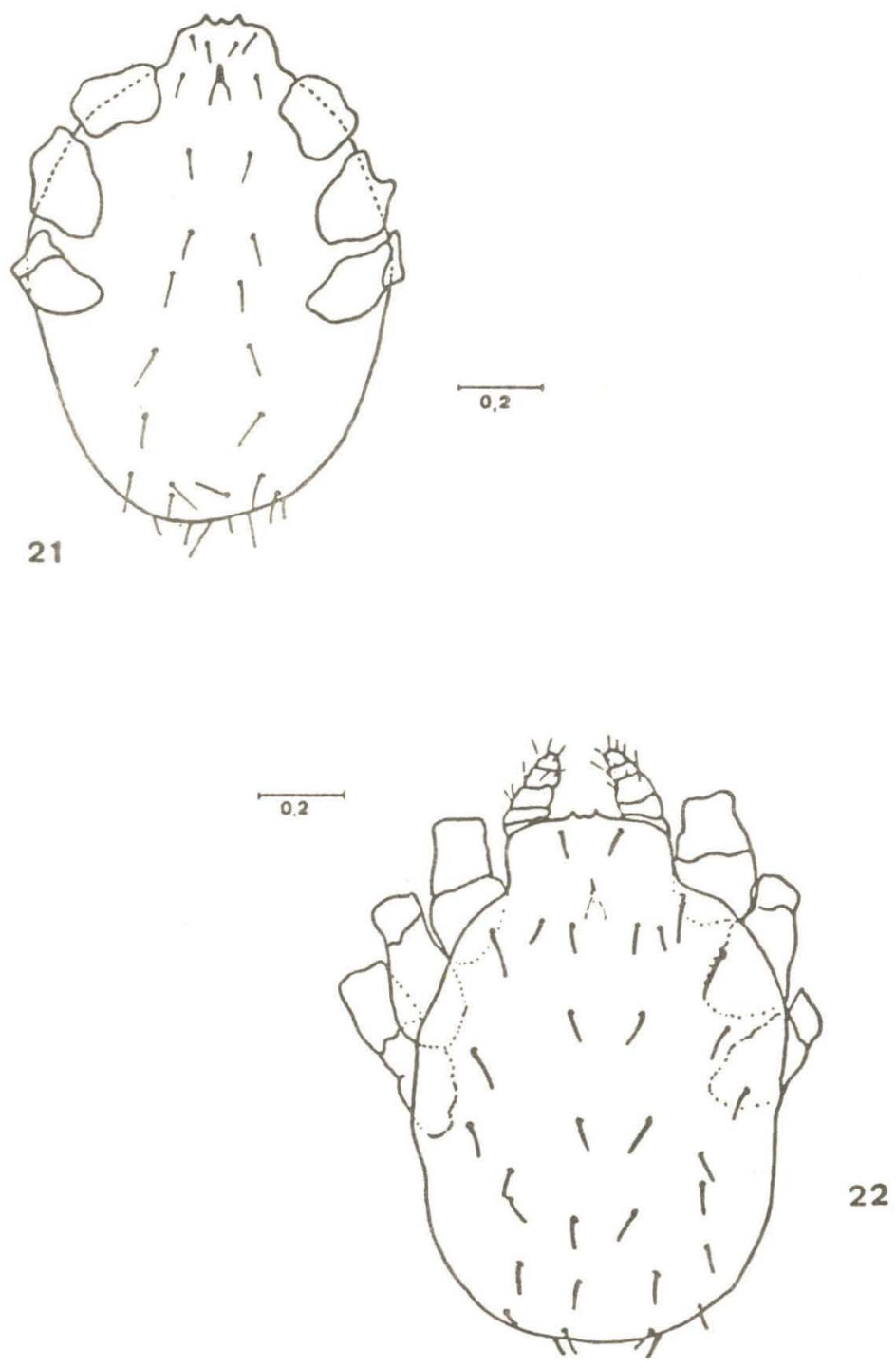

Spelaeorhynchus praecursor Neumann - Larva: Fig. 21 - Vista ventral; Fig. 22 - Vista dorsal. 
Spelaeorhynchus praecursor Neumann, 1902:31-37; Neumann, 1906:220; Neumann, 1911:136, figs. 71-76; Banks, 1915:70, fig. 133; Ewing, 1929:71; Radford, 1950a:375; Radford, 1950b:37; Baker \& Wharton, 1952:61, fig. 46; Vigueras, 1956:53; Aragão \& Fonseca, 1961:120; Taboada, 1965:10; Machado-Allison, 1967:369; Fain, Anastos, Camin \& Johnston, 1967:542-549, figs. 1, 2, 4-13; Dusbábek, 1970a:273; Dusbábek, 1970b:258-261, 5 figs.; Tamsitt \& Fox, 1970:1093-1094.

Spelaeorhynchus latus Banks, 1917:197-198, pl. 14, figs 6, 8; Fonseca, 1935:145-148; Fonseca, 1937:1580-1583; Radford, 1950a:375; Fonseca, 1958:55-58, 1 fig.; Taboada, 1965:10; Machado-Allison, 1967:369; Fain, Anastos, Camin \& Johnston, 1967:542, 547.

Spelaeorhynchus (?) latus: Fox, 1942:95-97.

Spelaeorhynchus cubanus Dias, 1958:27-29, 2 figs. ; Dusbábek, 1970 b:259.

Fêmea adulta: corpo achatado, mais estreito no gnatossoma, alargando-se progressivamente, atingindo o máximo da largura no terço anterior do opistossoma, margens di. reitas, exceto em pequeno trecho situado um pouco além dos peritremas, onde se apresentam levemente crenuladas.

Gnatossoma: Face dorsal convexa, nitidamente reticulada. Face ventral com 3 pares de espinhos, os dois pares mais internos, iguais, menores que o par mais externo, situado na região compreendida pela coxa dos palpos. Abertura do camerostômio sub-retangular, $\infty \mathrm{m}$ ângulos arredondados, mais larga que longa, apresentando leve intumescência na margem dorsal. Quelíceras robustas, dígitos com 2 dentes curtos, sub-triangulares, ligeiramente voltados para trás, sendo um mediano e outro a pical. Bordo posterior do dí. gito móvel com estreita área pregueada para a implantação de músculos. Palpos com as 2 cerdas dos trocanteres e as 2 cerdas laterais dos fêmures e dos joelhos muito modificadas, em forma de espátula. Cerdas espatuladas do trocanter com $44 \mu$ e $28 \mu$, do fêmur com $49 \mu$ e $36 \mu$, do joelho com $37 \mu$ e $30 \mu$. Tỉbia com as 2 cerdas dorsais do ápice longas e cilindricas. As demais cerdas dos palpos pectinadas na metade apical.

Idiossoma: anteriormente da largura do gnatossoma, alargando-se progressivamente até atingir o terço anterior do opistossoma, tornando-se arredondado a seguir e terminando em leve reentrância ao nivel da abertura anal. Face dorsal levemente convexa, margens laterais direitas, exceto em pequeno trecho situado pouco além dos peritremas onde se apresenta levemente crenulada. Escudo dorsal: mais longo que largo, com margem anterior reentrante, anteriormente da mesma largura que o gnatossoma, dilatando-se a seguir até atingir o máximo de sua largura ao nível da coxa II, estreitando-se depois e tornando-se arredondado posteriormente, um pouco além do nivel da coxa IV. Reentrância anterior do escudo provida de cutícula não esclerosada, dotada de 2 cerdas peri-escutais com $110 \mu$; ângulos anteriores arredondados, reforçados por espessamento conspícuo providos de 1 cerda escutal $(117 \mu)$ de cada lado; nas margens laterais 2 poros glandulares, situados pouco antes do ponto de maior largura do escudo; no disco com 6 pequenos poros glandulares dispostos em 2 fileiras medianas longitudinais. A cutícula em torno do escudo dorsal é conspicuamente mais esclerosada que o restante, e aí se inserem 6 cerdas peri-escutais $(114 \mu)$ de cada lado. A face dorsal do idiossoma apresenta 
ainda 4 pares de cerdas dorso-laterais com $120 \mu, 22$ a 25 pares de cerdas póstero-laterais com $120 \mu$, e 2 pares de cerdas póstero-dorsais com $134 \mu$. Face ventral plana, com margem anterior reentrante, onde se insere o gnatossoma. Ao nível da base da coxa I situa-se o escudo esternal, sub-triangular, fortemente esclerosado. Esse escudo apresenta dois conspicuos espessamentos internos, nos ângulos basais, que se ligam d̀s coxas I. A forma desse escudo sofre certa variação, podendo apresentar as suas margens ora côncavas, ora quase retas. Em frente à margem anterior do escudo esternal 1 par de cerdas peri-esternais com $65 \mu$. Lateralmente ocorrem mais 2 pares de cerdas, o primeiro esternal $(78 \mu)$, implantado no terço basal e o segundo peri-esternal $(90 \mu)$, próximo ao ápice. Observa-se ainda nesse escudo 2 pares de poros glandulares, o primeiro situado na margem anterior, junto aos espessamentos basais e o segundo pouco além das cerdas esternáis. Peritremas elípticos, localizados nas bordas laterais do podossoma, ao nível da coxa IV. Opistossoma com 7 a 8 pares de cerdas ventro-laterais, medindo $67 \mu$. Lateralmente, logo abaixo das coxas IV, curta area sub-triangular, onde a cutícula se apresenta nitidamente pregueada, conferindo às margens aspecto crenulado. Abertura genital guarnecida de 2 cerdas genitais com $92 \mu$. Abertura anal próxima à extremidade posterior, dotada de 3 cerdas anais com $58 \mu$, implantadas em pequenas áreas individuais levemente esclerosadas.

Comparamos medidas relacionadas com o comprimento do escudo esternal, do peritrema e das quelíceras e não achamos diferenças marcantes nas amostras disponíveis, conforme Quadro I.

Distribuição geográfica: BRASIL (Estados do Rio de Janeiro, São Paulo, Minas Gerais, Pernambuco); VENEZUELA, COLÔMBIA, PANAMÁ, GUATEMALA, HONDURAS BRITÂNICAS, MÉXICO, JAMAICA, PORTO RICO, REPÚBLICA DOMINICANA, CUBA.

Material examinado: BRASIL - Estado de São Paulo: 2 fêmeas, no 232, Instituto Butantan, S. Paulo, F. Fonseca col., 5.XI.1933, parasitando Glossophaga soricina, (IB); 1 fêmea, no 747, em álcool, Vila Clementino, S. Paulo, P. Guarizo leg., 22.VII.1936, em morcego não determinado, (EM); 2 fêmeas, Santos, S. Paulo, L. Travassos Filho leg., 20.III.1974, parasitando Carollia perspicillata, (UR); 1 larva, no. 232, retirada de uma fêmea colecionada no Instituto Butantan, S. Paulo, F. Fonseca col., 5.XI.1933, (IB); Estado do Rio de Janeiro: 7 fêmeas, no 1.132, Angra dos Reis, L. Travassos Filho col., VI.1937 (IB); 1 fêmea, no 522, Angra dos Reis, L. Travassos col., 1934, (IB); 1 fêmea, no 584 , em álcool, Angra dos Reis, L. Travassos col., 1934., parasitando Carollia perspicillata, (IB); 1 fêmea, no 1.084, em álcool, Angra dos Reis, L. Travassos Filho col., VI.1937, parasitando Glossophaga soricina, (EM); 1 fêmea, nọ 1.085, em álcool, Angra dos Reis, L. Travassos Filho col., VI.1937, parasitando Carollia perspicillata, (EM); 1 fêmea, Fonte Limpa, Itaguaí, A.1. Peracchi col., 11.I.1968, parasitando Carollia perspicillata, (UR); 2 fêmeas, Fonte Limpa, Itaguaí, A. L. Peracchi col., 11.I.1968, parasitando Anoura caudifer, (UR); 1 fền. ', Universidade Rural, Itaguai, A.L. Peracchi col., 26.VIII.1968, parasitando Carollia p rspicillata, (UR); 6 fêmeas, Universidade Rural, Itaguaí, A.L. Peracchi col., 27.IX.1968, parasitando Carollia perspicillata, (UR); 7 fê. meas, Fonte Limpa, Itaguai, A.L. Peracchi col., 7.XI.1968, parasitando Carollia perspicillata, (UR); 8 fềneas, Fonte Limpa, Itaguai, A.L. Peracchi col., 7.XI.1968, parasitando Anoura caudifer, (UR); 1 fêmea, Sá Freire, Itaguaí, A.L. Peracchi col., 6.I.1969, parasitando Carollia perspicillata, (UR); 1 fêmea, Belvedere, Itaguaí, A.L. Peracchi col., 21.IX.1971, parasitando Anoura caudifer, (UR); 2 fêmeas, Belvedere, Itaguaí, A.L. Peracchi col., 6.X.1971, parasitando Glossophaga soricina, (UR); 2 fêmeas, Belvedere, 
Revta bras. Zool.

Itaguaí, A.L. Peracchi col., 6.X.1971, parasitando Anoura caudifer, (UR); 7 fêmeas, Fonte Limpa, Itaguai, A.L. Peracchi col., 13.I.1969, parasitando Carollia perspicillata, (UR); 1 fềmea, Sá Freire, Itaguaí, A.L. Peracchi col., 27.VII.1974, parasitando Carollia perspicillata, (UR); 6 larvas, retirddas de fêmeas colecionadas em Fonte Limpa, Itaguai, em 7.XI.1968, (UR); Estado de Minas Gerais: 1 fêmea, no 532, Benjamin Constant, E. Dias col., sem data, parasitando Hemiderma perspicillata, (IB); 1 fêmea, no 580 , em álcool, Lassance, F. Fonseca col., 15.IX.1934, (IB); VENEZUELA - 1 fêmea, Zulia, Peterson, Brown \& Matson col., 15.IV.1968, parasitando Anoura geoffroyi, (BY); 3 fêmeas, Zulia, Peterson, Brown \& Matson col., 17.IV.1968, parasitando Carollia sp., (BY); 2 fêmeas, Carabobo, Tuttle col., 23-27.XI.1967, parasitando Carollia perspicillata ,(BY); 1 fêmea, Carabobo, Tuttle col., 27.XI.1967, parasitando Anoura geoffoyi, (BY); 9 fêmeas, Bolivar, Tuttle col., 20-30.IV.1968, parasitando Carollia sp., (BY); 3 fêmeas, Bolivar, Tuttle col., 1.V.1968, parasitando Carollia sp., (BY); 2 fêmeas, Bolivar, Tuttle col., 5.V.1968, parasitando Carollia sp., (BY); 3 fêmeas, Bolivar, Tuttle col., 6.V.1968, parasitando Carollia perspicillata, (BY); HONDURAS BRITÂNICAS - 4 fêmeas, Belize, I.T. Sanderson col., 5.X.1939, (FM); GUATEMALA - 3 fêmeas, Moco, Sololá, F.J.W. Schmidt col., 10.I.1934, parasitando Carollia perspicillata asteca, (FM); MÉXICO - 5 fêmeas, Tekom, Yucatan, I.T. Sanderson col., 27.IV.1940, “on tragus of ear”, (FM); JAMAICA - 3 fêmeas, Sherwood Forest, I.T. Sanderson col., 28.VIII.1939, parasitando Artibeus jamaicensis jamaicensis, (FM); 24 fêmeas, Sherwood Forest, I.T. Sanderson col., 9.IX.1939, parasitando Artibeus jamaicensis jamaicensis, (FM).

Comentários: todos os exemplares que tivemos a oportunidade de colecionar estavam firmemente fixados aos tecidos do trago ou da base da orelha dos hospedeiros.

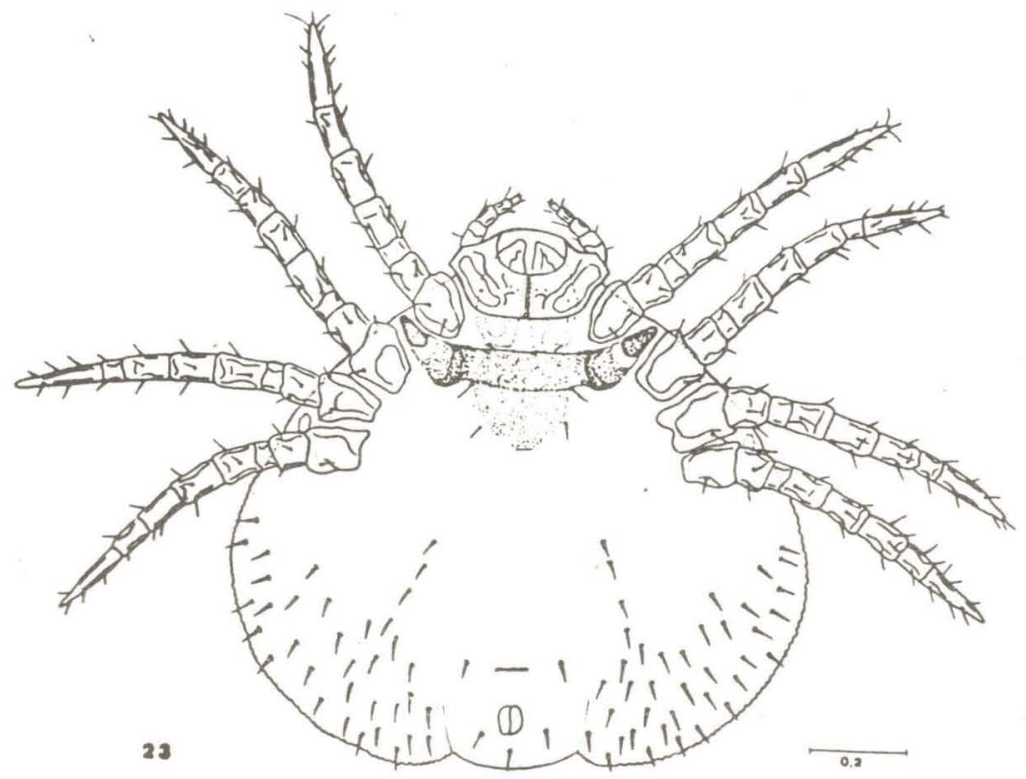

Spelaeorhynchus jimi sp. n.:Fig. 23 - Vista ventral da fêmea. Escalas em mm. 
Vol. 7(1-2), 1990
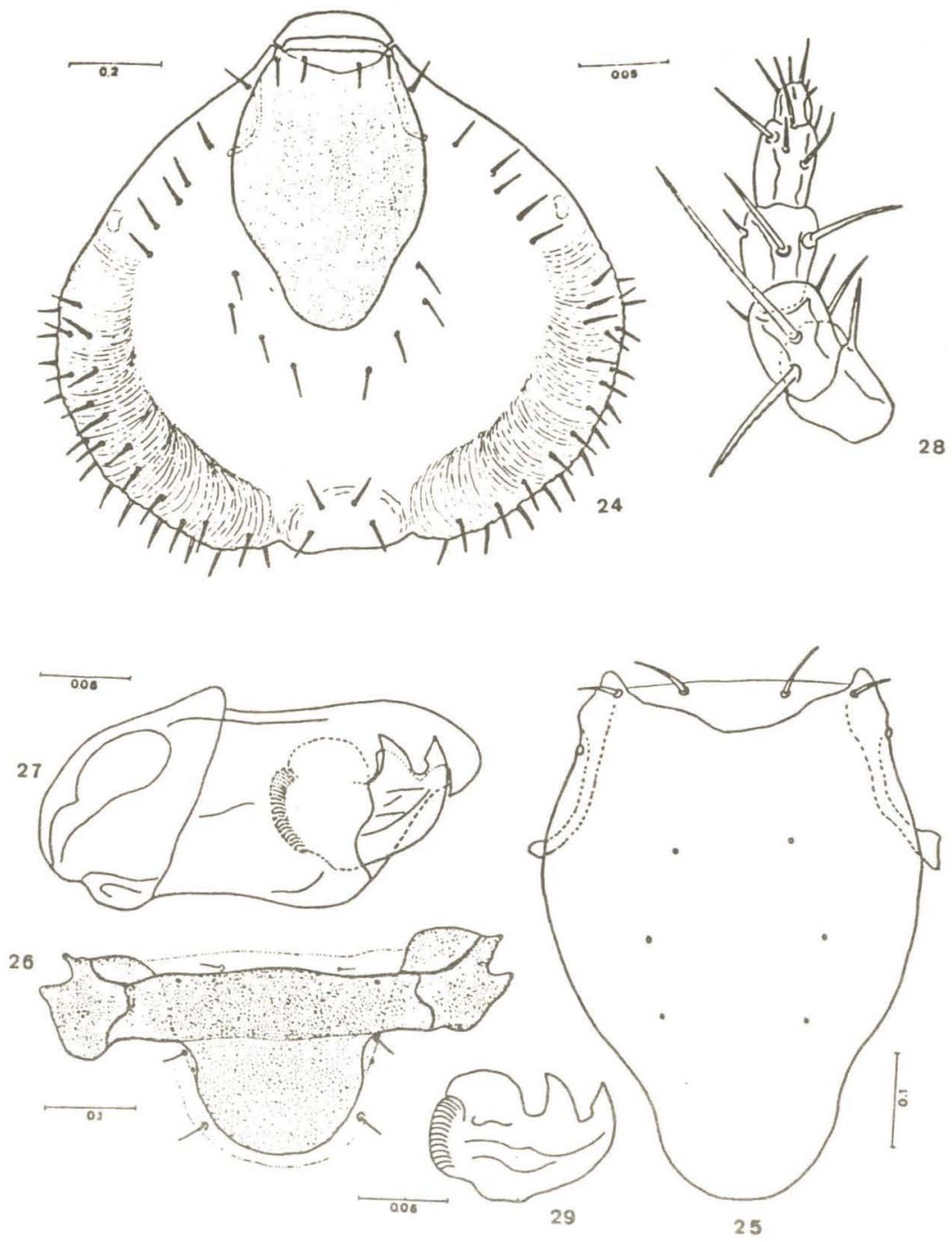

Spelaeorhynchus jimi sp. n. - Fêmea adulta: Fig. 24 - Vista dorsal; Fig. 25 - Escudo dorsal; Fig. 26 - Escudo esternal; Fig. 27 - Quelícera; Fig. 28 - Vista dorsal do palpo; Fig. 29 - Dígito móvel. Escalas $\mathrm{cm} \mathrm{mm}$. 
Revta bras. Zool.

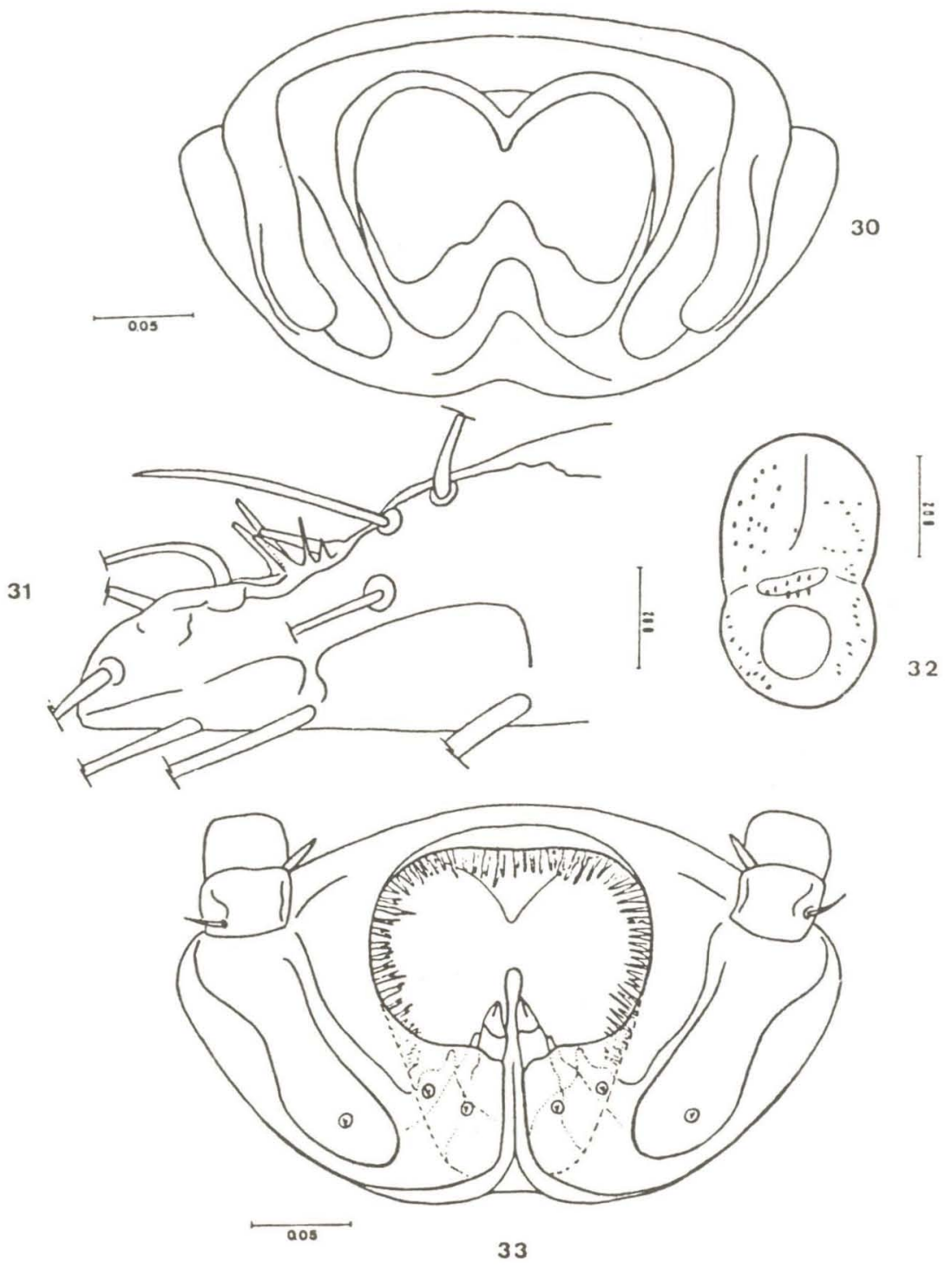

Spelaeorhynchus jimi sp. n. - Fêmea adulta:Fig. 30 - Gnatossoma visto por trás; Fig. 31 - Vista lateral da extremidade do tarso I; Fig. 32 - Peritrema; Fig. 33 - Gnatossoma visto de frente. Escalas em $\mathrm{mm}$. 

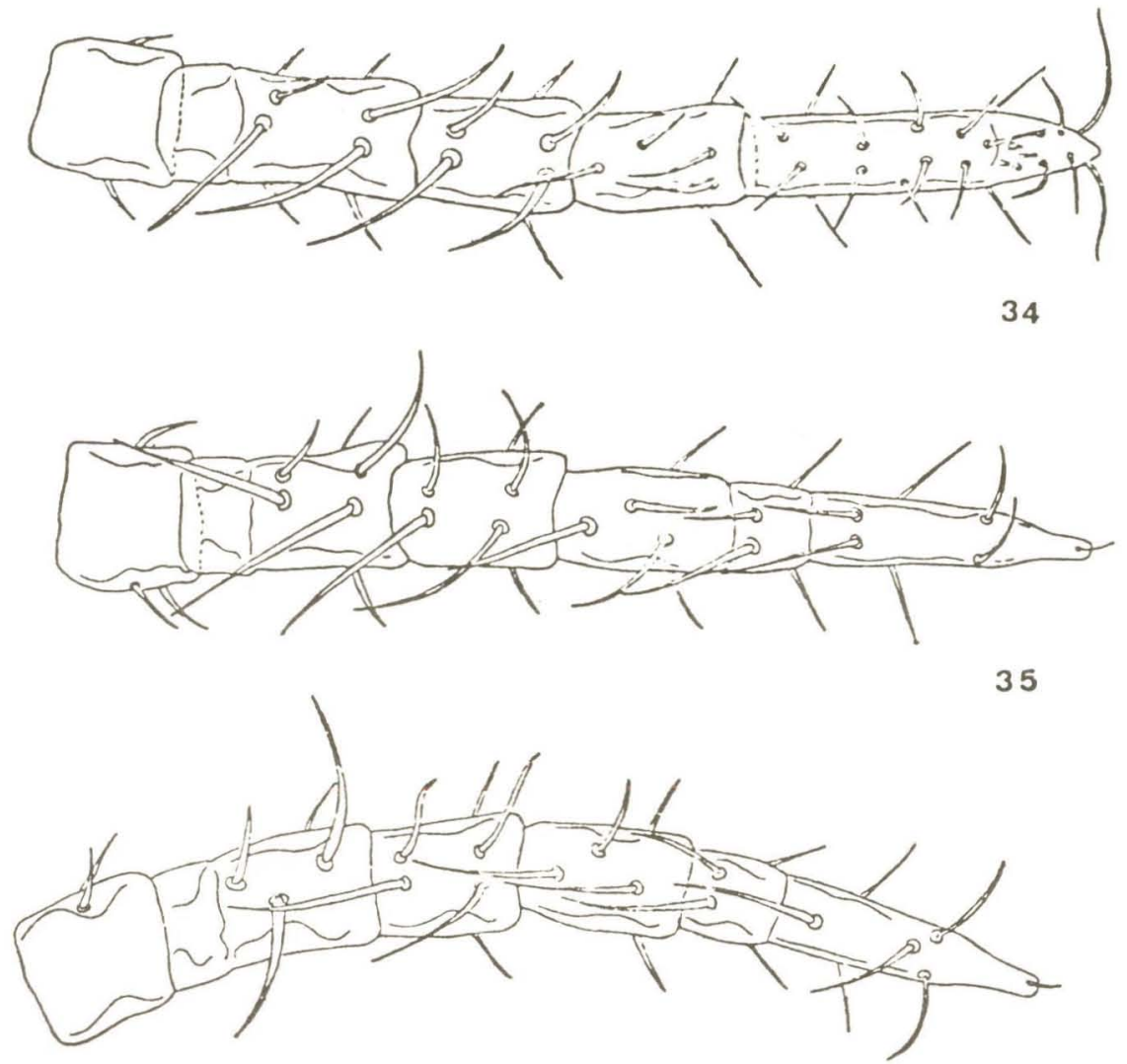

36

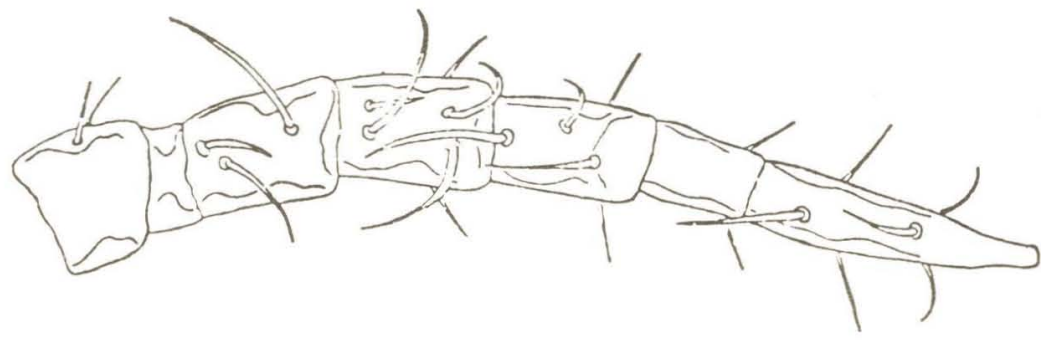

(1)

Spelaeorhynchus jimi sp. n. - Fêmea adulta: Fig. 34 - Vista dorsal da pata I; Fig. 35 - Vista dorsal da pata II; Fig. 36 - Vista dorsal da pata III; Fig. 37 - Vista dorsal da pata IV. Escalas em mm. 


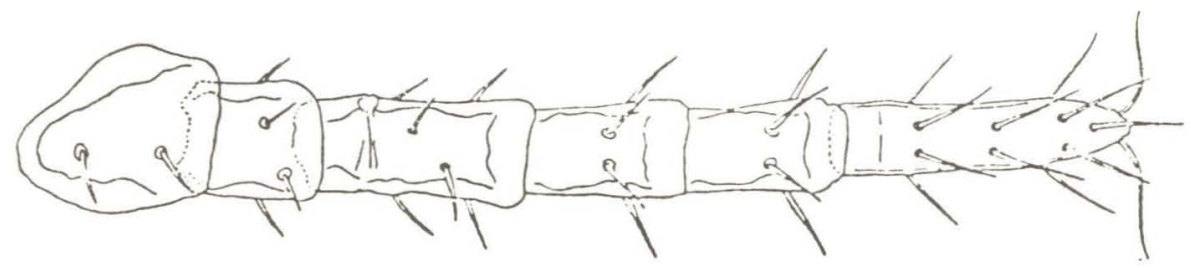

38
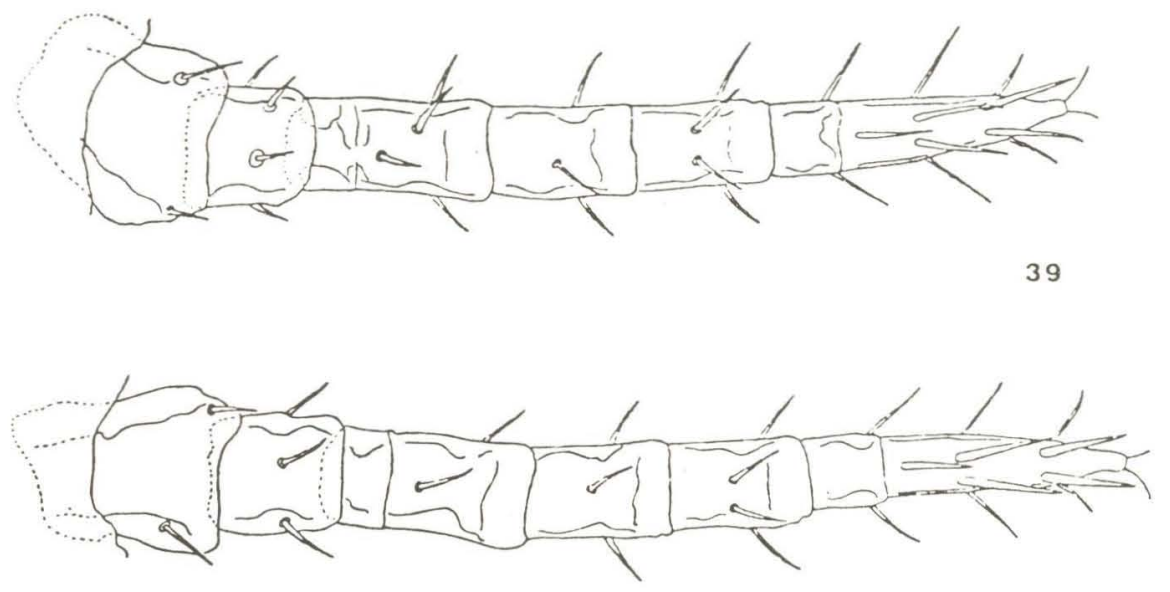

40

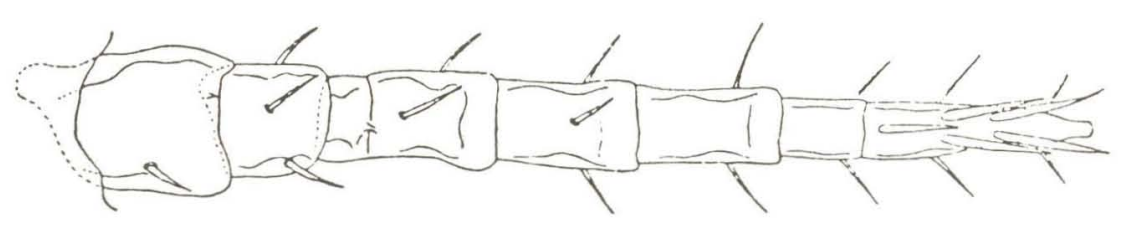

41

11

Spelaeorhynchus jimi sp. n. - Fêmea adulta:Fig. 38 - Vista ventral da pata I;Fig. 39 - Vista ventral da pata II; Fig. 40 -Vista ventral da pata III; Fig. 41 - Vista ventral da pata IV. Escalas em mm. 
Vol. $7(1-2), 1990$

\section{Spelaeorhynchus jimi sp.n.}

(Figs. 23 a 41)

Fêmea adulta: corpo achatado sub-circular, mais estreito no gnatossoma, alargando-se progressivamente e atingindo o máximo da largura na metade do opistossoma; margens do podossoma direitas e do opistossoma distintamente crenuladas, formando duas reentrâncias conspícuas na extremidade posterior, o que confere à região anal o aspecto de pequeno lóbulo.

Gnatossoma: largura $=0,350 \mathrm{~mm}$. Face dorsal quase plana, lisa, desprovida de escultura. Face ventral com 3 pares de pequeninos espinhos, dos quais o par interno é ligeiramente menor que os demais. Abertura do camerostômio sub-retangular, com ângulos arredondados, mais larga que longa, bordo basal com reentrância no meio. Quelíceras robustas, dígitos com 2 dentes bem desenvolvidos, ligeiramente voltados para trás, um apical e o outro mediano. Dígito móvel com bordo posterior dotado de área pregueada para a im. plantação de músculos. Palpos desprovidos de cerdas espatuladas.

Idiossoma : comprimento $=1,048 \mathrm{~mm}$, largura $($ ao nível do peritrema $)=0,906 \mathrm{~mm}$. Face dorsal ligeiramente convexa, apresentando os bordos laterais do opistossoma formando rebordo largo, que se estende da região do peritrema até a reentrância delimitante do lóbulo anal. Nesse rebordo a cutícula apresenta estrias largas, perpendiculares à margem, enquanto que no restante da face dorsal essas estrias são praticamente paralelas às margens. Escudo dorsal mais longo que largo, com margem anterior reentrante, reentrância dotada de cutícula não esclerosada onde se inserem 2 longas cerdas peri-escutais $(130 \mu)$; ângulos anteriores arredondados, reforçados por espessamento conspícuo, salientes, providos de 2 cerdas escutais $(112 \mu)$; logo abaixo dos ângulos anteriores 1 par de poros glandulares; margens laterais curvas, inicialmente divergentes, atingindo o maior afastamento no terço basal, convergindo a seguir, reentrantes no terço apical, unindo-se posteriormente em grande ângulo arredondado. Em torno do escudo dorsal ocorrem 6 pares de cerdas peri-escutais $(67 \mu)$. A face dorsal apresenta ainda 4 pares de cerdas dorso-laterais $(86 \mu), 32$ a 35 pares de cerdas póstero-laterais $(104 \mu)$ e 2 pares de cerdas póstero-dorsais $(76 \mu)$. Face ventral plana, a margem anterior com reentrância sub-retangular, onde se insere o gnatossoma. Entre a margem e o escudo esternal a cut ícula apresenta-se ornada com numerosos espinhos, dispostos compactamente e em filas transversais. Cutícula do lóbulo anal finamente estriada, todas as estrias convergindo para a abertura genital enquanto o restante do opistossoma apresenta estrias largas e profundas, que partindo das crênulas marginais convergem, de cada lado, para um ponto interno, lateral à coxa IV. Escudo esternal mais largo que longo, finamente pontuado, formado na base por área aproximadamente retangular e no ápice por expansão mediana, subquadrada, de ângulos arredondados; a área basal, distintamente mais esclerosada que a apical, apresenta nos bordos laterais fortes espessamentos internos, que se articulam com pequena projeção cônica, de ápice arredondado e de margem externa crenulada, existente entre as coxas I e II. Em torno do escudo esternal existem 2 pares de cerdas peri-esternais, o primeiro $(29 \mu)$ situado adiante do bordo anterior e o segundo $(41 \mu)$ lateral, inserido próximo ao bordo posterior. O escudo esternal é dotado de 2 cerdas esternais $(40 \mu)$, localizadas no ângulo formado pela junção das áreas basal e apical, bem como apresenta 4 poros glandulares, 2 situados na margem anterior e 2 laterais, localizados logo abaixo das cerdas esternais. Abertura genital em forma de fenda transversal, guarnecida por 1 par de cerdas genitais $(48 \mu)$. Ânus arredondado, situado no lóbulo 
anal, próximo a extremidade posterior, provido de fenda longitudinal. Em torno do ânus ocorrem 3 cerdas anais $(68 \mu)$ inseridas em 3 pequeninas placas levemente esclerosadas. $\mathrm{Na}$ face ventral ocorrem 10 a 12 cerdas ventro-laterais $(30 \mu)$. Peritremas (comprimento $=0,054 \mathrm{~mm}$, largura $=0,037 \mathrm{~mm}$ ) situados ao nivel da coxa IV, elipticos, com uma reentrância em cada bordo lateral, o que lhe confere o aspecto de um " 8 ".

Distribuição geográfica: Brasil.

Material tipo: Holótipo - fêmea; Córrego dos Índios, Xavantina, Mato Grosso, Brasil; J. Jim col.; 15-16. VII. 1968; parasitando Micronycteris megalotis (Gray, 1842); na coleção da Área de Zoologia, Instituto de Biologia, Universidade Federal Rural do Rio de Janeiro.

Parátipos: 42 fêmeas, mesmos dados do holótipo, sendo que 6 fêmeas estão depositadas no Field Museum, 3 no Instituto Butantan e o restante na coleção da Área de Zoologia, Instituto de Biologia, Universidade Federal Rural do Rio de Janeiro.

S. jimi sp. n. distingue-se das demais espécies até então conhecidas pela forma do escudo esternal, por apresentar a face dorsal do gnatossoma lisa e por ser desprovida de cerdas espatuladas nos palpos.

Comentários: todos os exemplares examinados foram por nós colecionados sobre 3 espécimens de Micronycteris megalotis que forneceram 10,16 e 17 acarinos, respectivamente. Estes estavam firmemente fixados à pele do hospedeiro e foram encontrados tanto no dorso, como na região gular dos quirópteros. Os hospedeiros foram depositados na coleção do autor.

Dedicamos o nome específico ao Dr. Jorge Jim, do Departamento de Zoologia da UNESP, Campus de Botucatu, S. Paulo.

\section{Spelaeorhynchus soaresi $\mathrm{sp}$. n.}

(Figs. 42 a 51 )

Fêmea adulta: corpo achatado, sub-circular, mais estreito no gnatossoma, dilatando-se a seguir, atingindo o máximo da largura na metade do opistossoma, margens direitas.

Gnatossoma: Largura $=0,474 \mathrm{~mm}$. Face dorsal levemente convexa, distintamente reticulada. Face ventral com 3 pares de pequeninos espinhos. Abertura do camerostômio sub-quadrada, tão longa quão larga, com ângulos arredondados, apresentando ligeiro entumescimento na margem dorsal. Quelíceras robustas, dígitos $00 \mathrm{~m} 2$ dentes curtos, subtriangulares, voltados para trás, sendo um mediano e o outro apical. Dígito móvel com bordo pregueado para a inserção de músculos. Palpos com 6 cerdas espatuladas, sendo 2 no trocantes $(27 \mu$ e $14 \mu), 2$ no fêmur $(32 \mu \mathrm{e} .21 \mu)$ e 2 no joelho $(25 \mu$ e $11 \mu)$. As 2 cerdas apicais dorsais da tíbia, longas e cilíndricas; demais cerdas dos palpos pectinadas na metade apical.

Idiossoma : Comprimento $=1,490 \mathrm{~mm}$, largura $($ ao nível do peritrema $)=1,484 \mathrm{~mm}$. Anteriormente da largura do gnatossoma, dilatando-se progressivamente até alcançar a metade do opistossoma, arredondado a seguir, ligeiramente sinuoso no ápice, margens direitas. Face dorsal suavemente convexa. Escudo dorsal ligeiramente mais longo que largo, com margem anterior reentrante, da mesma largura que o gnatossoma, margens laterais nitidamente reentrantes no terço anterior, convexas no terço mediano e levemente sinuosas a seguir, formando ângulo arredondado no ápice. Reentrância anterior guarnecida com 2 cerdas peri-escutais $(120 \mu)$; ângulos anteriores arredondados, dotados de crda escutal $(117 \mu)$, apresentando conspícuos espessamentos internos; nas áreas adja- 
centes às margens laterais 6 pares de cerdas peri-escutais $(140 \mu)$. A face dorsal do idiossoma apresenta ainda 4 pares de cerdas dorso-laterais $(120 \mu), 30$ a 34 pares de cerdas póstero-laterais $(120 \mu)$ e 2 pares de cerdas póstero-dorsais $(100 \mu)$. Face ventral plana, com reentrância anterior onde se insere o gnatossoma. Escudo esternal situado ao nível da coxa I, mais largo que longo, formado por uma área basal muito estreita, transversal, nitidamente mais esclerosada que o restante e uma área apical, sub-triangular, de ápice arredondado. A base do escudo apresenta dois espessamentos internos que se articulam com a coxa I. Escudo esternal com área adjacente à margem anterior dotada de 1 par de cerdas peri-esternais $(54 \mu)$; lateralmente com 2 pares de cerdas, o primeiro esternal $(80 \mu)$ e o segundo peri-esternal $(87 \mu)$ próximo ao ápice. Junto a cada cerda esternal 1 poro glandular. Na margem anterior do escudo, junto aos espessamentos laterais, 1 poro glandular de cada lado; próximo às cerdas esternais, um segundo par de poros glandulares. Peritremas (comprimento $=0,081 \mathrm{~mm}$; largura $=0,049 \mathrm{~mm}$ ) elípticos, localizados ao nível da coxa IV. Opistossoma com 7 a 9 pares de cerdas ventro-laterais $(58 \mu)$. Abertura genital dotada de 2 cerdas genitais $(78 \mu)$; abertura anal localizada próximo à borda posterior do opistossoma, com 3 cerdas anais $(64 \mu)$.

Distribuição geográfica: Peru.

Material tipo: Holótipo - fêmea; Puno, Segrario, Peru; C.C. Sanborn col.; 10.X.1941; parasitando Carollia sp.; na coleção do Field Museum of Natural History, Chicago, EUA.

Parátipos: 4 fêmeas, mesmos dados do holótipo, sendo que 2 fềmeas estão depositadas no Field Museum e 2 na coleção da Área de Zoologia, Instituto de Biologia, Universidade Federal Rural do Rio de Janeiro.

$S$. soaresi sp.n. aproxima-se de $S$. jimi sp.n., por apresentar escudo esternal mais largo que longo, formado na base por área estreita, nitidamente mais esclerosada que o restante; contudo, dela se distingue por apresentar palpos com cerdas espatuladas e face dorsal do gnatossoma reticulada.

Dedicamos o nome específico ao saudoso Dr. Benedicto Abílio Monteiro Soares, do Departamento de Zoologia da UNESP, Campus de Botucatu, S. Paulo, pela dedicação com que orientou os nossos primeiros passos na pesquisa.

\section{Spelaeorhynchus wenzeli sp.n.}

(Figs. 52 a 61)

Fêmea adulta: corpo achatado, sub-circular, mais estreito no gnatossoma, alargando-se progressivamente, atingindo o máximo da largura na metade do opistossoma, margens do idiossoma direitas.

Gnatossoma: largura $=0,498 \mathrm{~mm}$. Face dorsal levemente convexa, nitidamente reticulada. Abertura do camerostômio subretangular, com ângulos arredondados, mais larga que longa. Quelíceras robustas, dígitos com 2 dentes curtos, subtriangulares, os medianos voltados para trás. Dígito móvel com área pregueada no bordo posterior para inserção de músculos. Palpos com 5 cerdas laterais estreitas e espatuladas, 1 no trocanter $(33 \mu), 2$ no fêmur $(38 \mu$ e $30 \mu)$ e 2 no joelho $(37 \mu$ e $25 \mu)$. Tíbia com as 2 cerdas dorsais e apicais, longas e cilíndricas; demais cerdas dos palpos pectinadas na metade apical.

Idiossoma: Comprimento $=1,610 \mathrm{~mm}$, largura (ao nível do peritrema) $=1,298 \mathrm{~mm}$, anteriormente da largura do gnatossoma, dilatando-se progressivamente até alcançar a maior largura na metade do opistossoma, arredondado a seguir. Face dorsal ligeiramente convexa. Escudo dorsal mais longo que largo; com margem anterior côncava, da mesma 
largura que o gnatossoma; margens laterais convexas no terço anterior, atingindo o escudo o máximo da largura um pouco além do nível da coxa IV; ângulos anteriores com nítido espessamento interno que se estende no terço lateral anterior do escudo, ultrapassando as margens do mesmo; nesse ponto a cutícula se apresenta levemente mais esclerosada que o restante, tomando o aspecto de asa irregular. Ângulos anteriores do escudo dotados de cerda escutal com $115 \mu$; área adjacente à margem anterior do escudo com 1 par de cerdas peri-escutais com $115 \mu$; ao lado das margens laterais 5 pares de cerdas periescutais com $120 \mu$. Face dorsal do idiossoma guarnecida com 4 pares de cerdas dorsolaterais $(140 \mu)$, com 34 a 38 pares de cerdas póstero-laterais $(120 \mu)$ e com 2 pares de cerdas póstero-dorsais $(105 \mu)$. Face ventral plana, com margem anterior reentrante, onde se insere o gnatossoma. Ao nível da coxa I situa-se o escudo esternal, muito mais largo que longo, formado na base por área levemente curva, em forma de retângulo alongado, muito estreita, nitidamente mais esclerosada que o ápice; este semicircular e tende a desaparecer no material clarificado em face da fraca esclerotização. Área basal do escudo dotada de dois espessamentos laterais internos que se articulam nitidamente com a coxa I. Em frente à margem anterior do escudo 1 par de cerdas peri-esternais $(68 \mu) \mathrm{e}$ lateralmente à área semi-circular, 2 pares, sendo 1 par de cerdas esternais $(70 \mu)$ e o outro de cerdas peri-esternais $(98 \mu) ; 2$ pares de poros glandulares, o primeiro situado na margem anterior, junto aos espessamentos internos e o segundo próximo ao par de cerdas esternais. Peritremas (comprimento $=0,083 \mathrm{~mm}$; largura $=0,041 \mathrm{~mm}$ ) elípticos, com ligeira reentrância no bordo lateral interno, situados ao nível da coxa IV. Opistossoma com 5 a 6 pares de cerdas ventro-laterais $\operatorname{com} 66 \mu$. Abertura genital guarnecida com 2 cerdas genitais $(100 \mu)$ e abertura anal situada próximo à borda posterior, provida de 3 cerdas anais $(70 \mu)$.

Distribuição geográfica: Colômbia.

Material tipo: Holótipo - fêmea; Nariño, La Guyacana, Colòmbia; Kjell von Sneidem col.; 3.III.1958; parasitando Carollia perspicillata; na coleção do Field Museum of Natural History, Chicago, EUA.

Parátipos: 6 fêmeas, mesmos dados do holótipo, sendo que 4 fêmeas estão dẹpositadas no Field Museum e 2 na coleção da Área de Zoologia, Instituto de Biologia, Universidade Federal Rural do Rio de Janeiro.

$S$. wenzeli sp.n., cujo nome específico é dedicado ao Dr. Rupert L. Wenzel, aproxima-se de $S$. soaresi sp.n., por apresentar a face dorsal dognatossoma reticulada, cerdas espatuladas nos palpos e escudo esternal com área basal estreita; contudo, dela se distingue por apresentar trocanter dos palpos com uma única cerda espatulada, escudo dorsal com margens laterais convexas no terço anterior, cerdas espatuladas dos palpos mais longos e estreitas e parte apical do escudo esternal semicircular.

Spelaeorhynchus monophylli Fain, Anastos, Camin \& Johnston,

1967: 549-552, figs. 15 a 21; Tamsitt \& Fox, 1970: 1094; Tamsitt \& Valdivieso, 1970:125-126.

Distribuição geográfica: Porto Rico.

Hospedeiro: Monophyllus portoricensis (= Monophyllus redmani portoricensis).

Comentários: não tivemos a oportunidade de examinar material dessa espécie; contudo, ela se distingue das demais espécies do gênero por apresentar escudo esternal en. volvido lateralmente por área de cutícula nitidamente esclerosada.

Spelaeorhynchus chilonycteris Fain, Anastos, Camin \& Johnston, 1967:

552-553, figs. 22 a 25. 
Vol. 7(1-2), 1990

Distribuição geográfica: Guatemala.

Hospedeiro: Chilonycteris rubiginosa rubiginosa.

Comentários: não examinamos material dessa espécie; entretanto, ela se separa das demais espécies do gênero por apresentar a face dorsal do gnatossoma ornada com 8 linhas longitudinais.

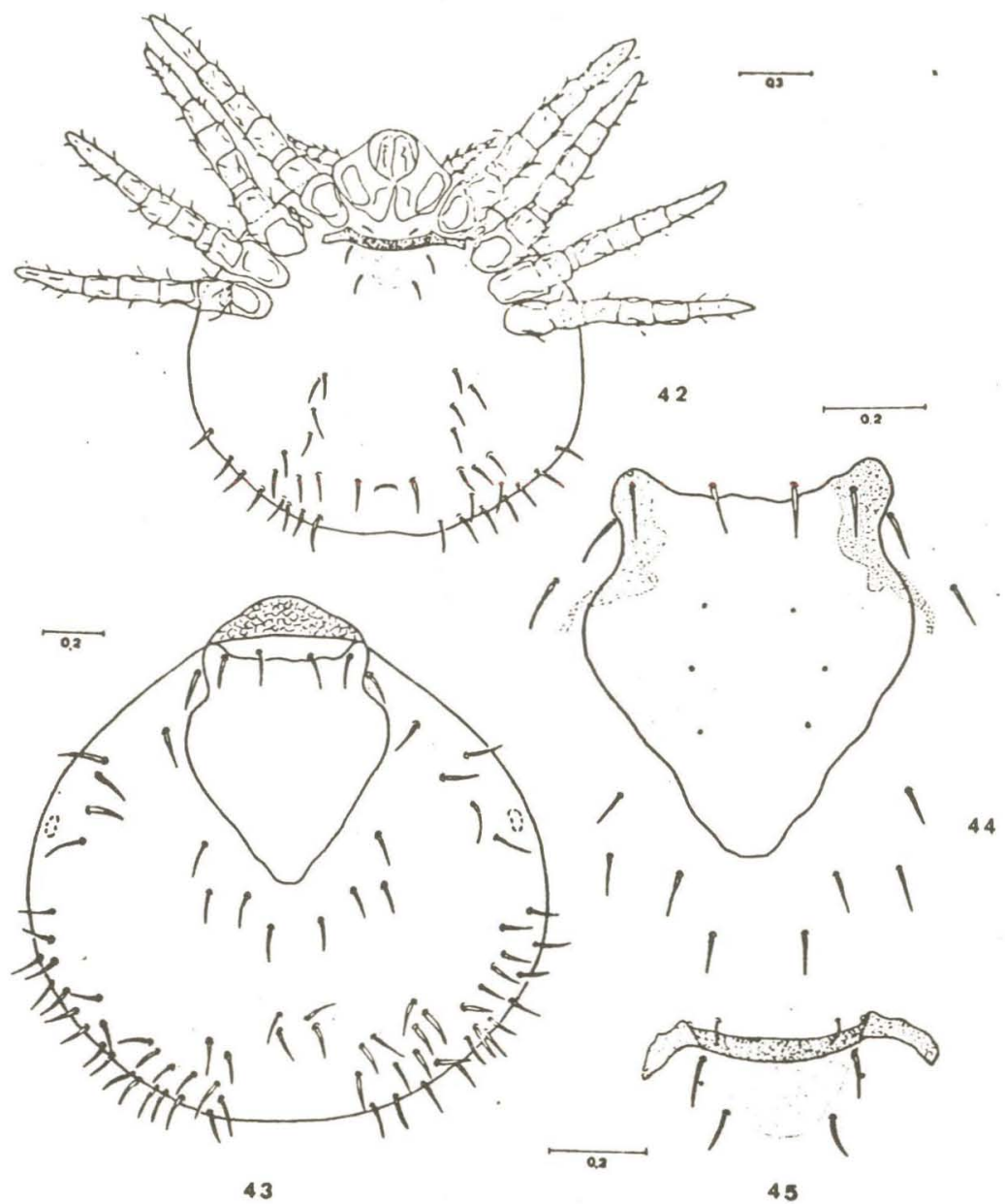

Spelaeorhynchus soaresi sp. n. - Fêmea adulta: Fig. 42 - Vista ventral; Fg. 43 - Vista dorsal; Fig. 44 - Escudo dorsal; Fig. 45 - Escudo esternal. Escalas em mm. 
Revta bras. Zool.
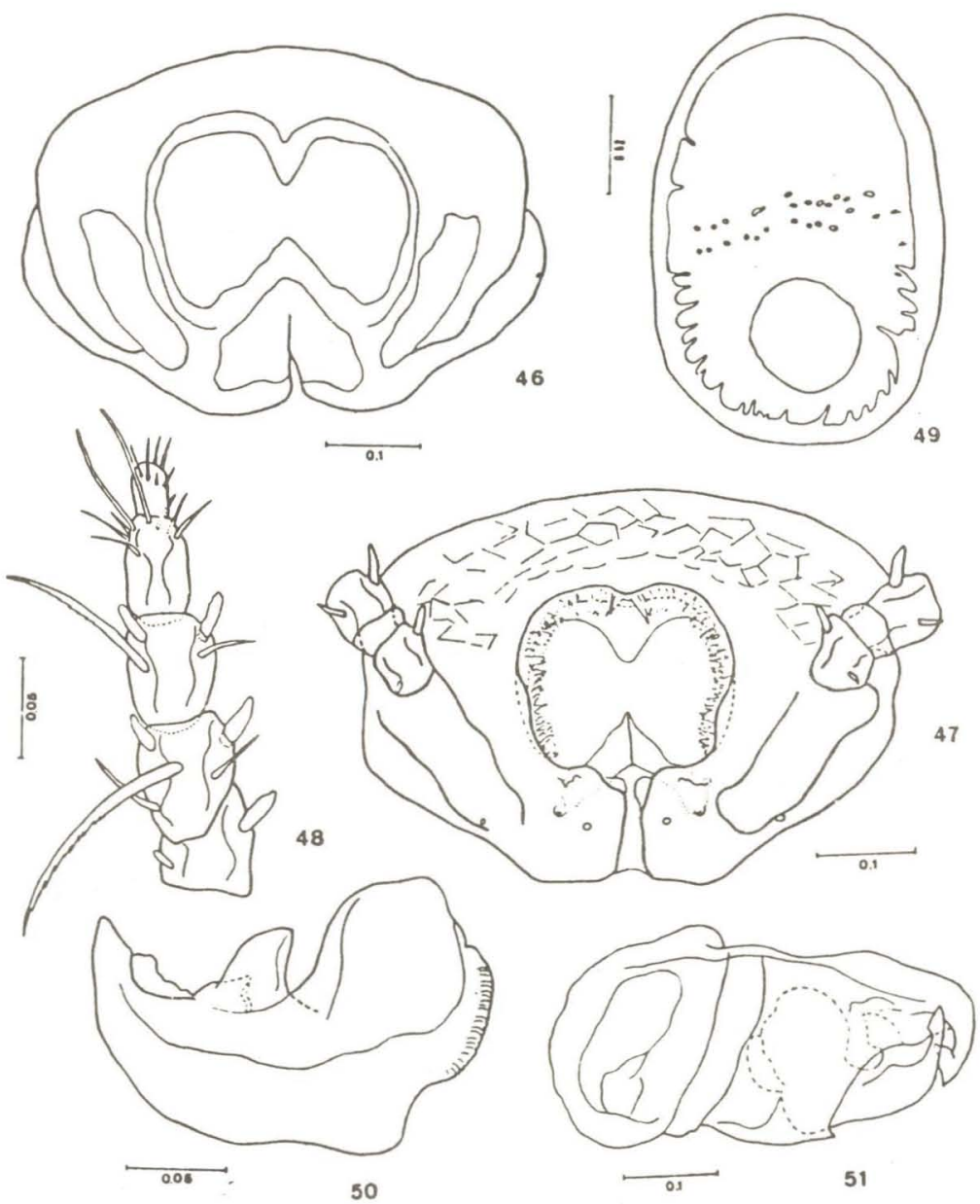

Spelaeorhynchus soaresi sp. n. - Fêmea adulta:Fig. 46 - Gnatossoma visto por trás; Fig. 47 - Gnatossoma visto de frente; Fig. 48 - Vista dorsal do palpo; Fig. 49 - Peritrema; Fig. 50 - Dígito móvel; Fig. 51 - Quelícera. Escalas em mm. 
Vol. 7(1-2), 1990

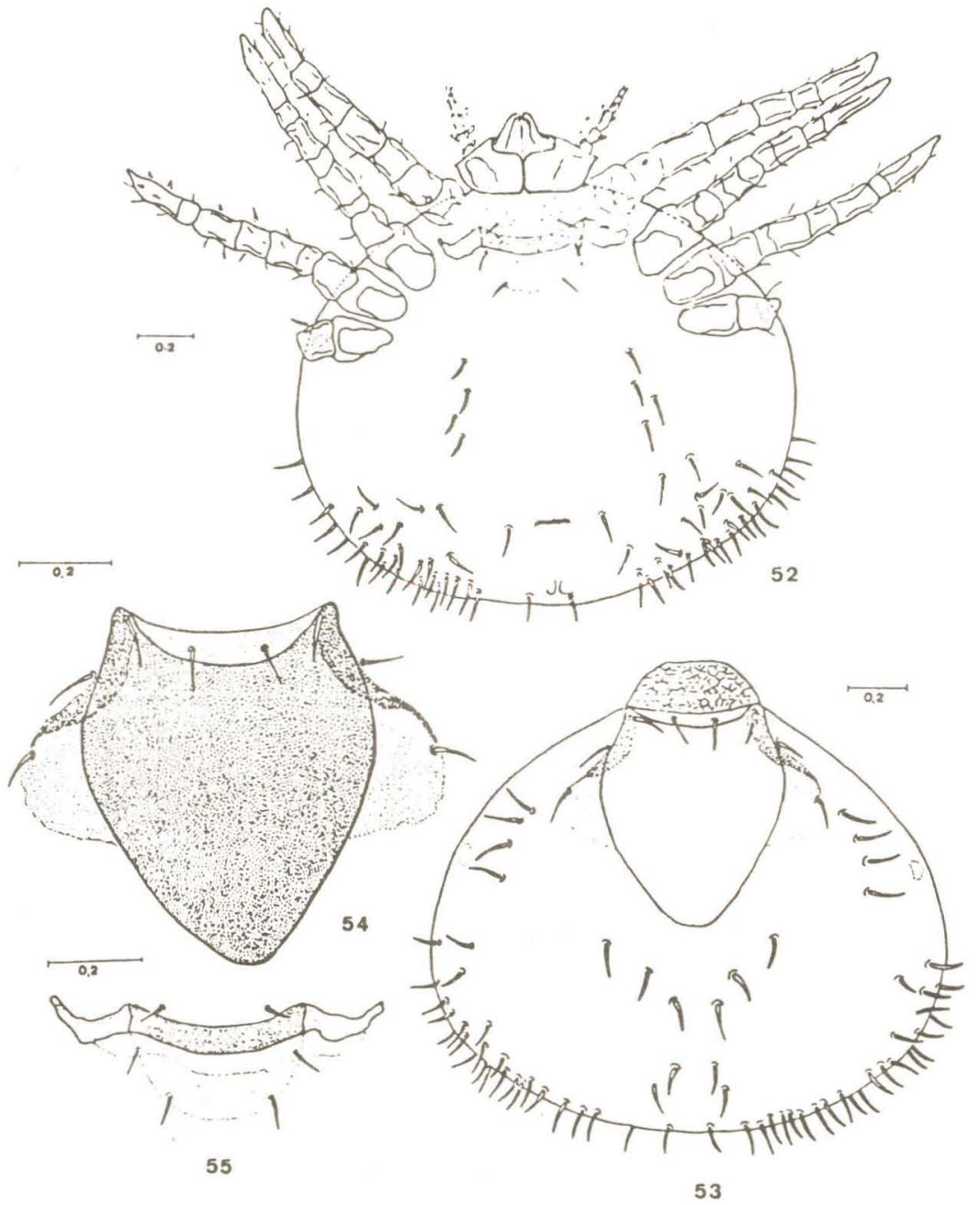

Spelaeorhynchus wenzeli sp. n. - Fêmea adulta: Fig. 52 - Vista ventral; Fig. 53 - Vista dorsal; Fig. 54 - Escudo dorsal; Fig. 55 - Escudo esternal. Escalas em mm. 
Revta bras. Zool.
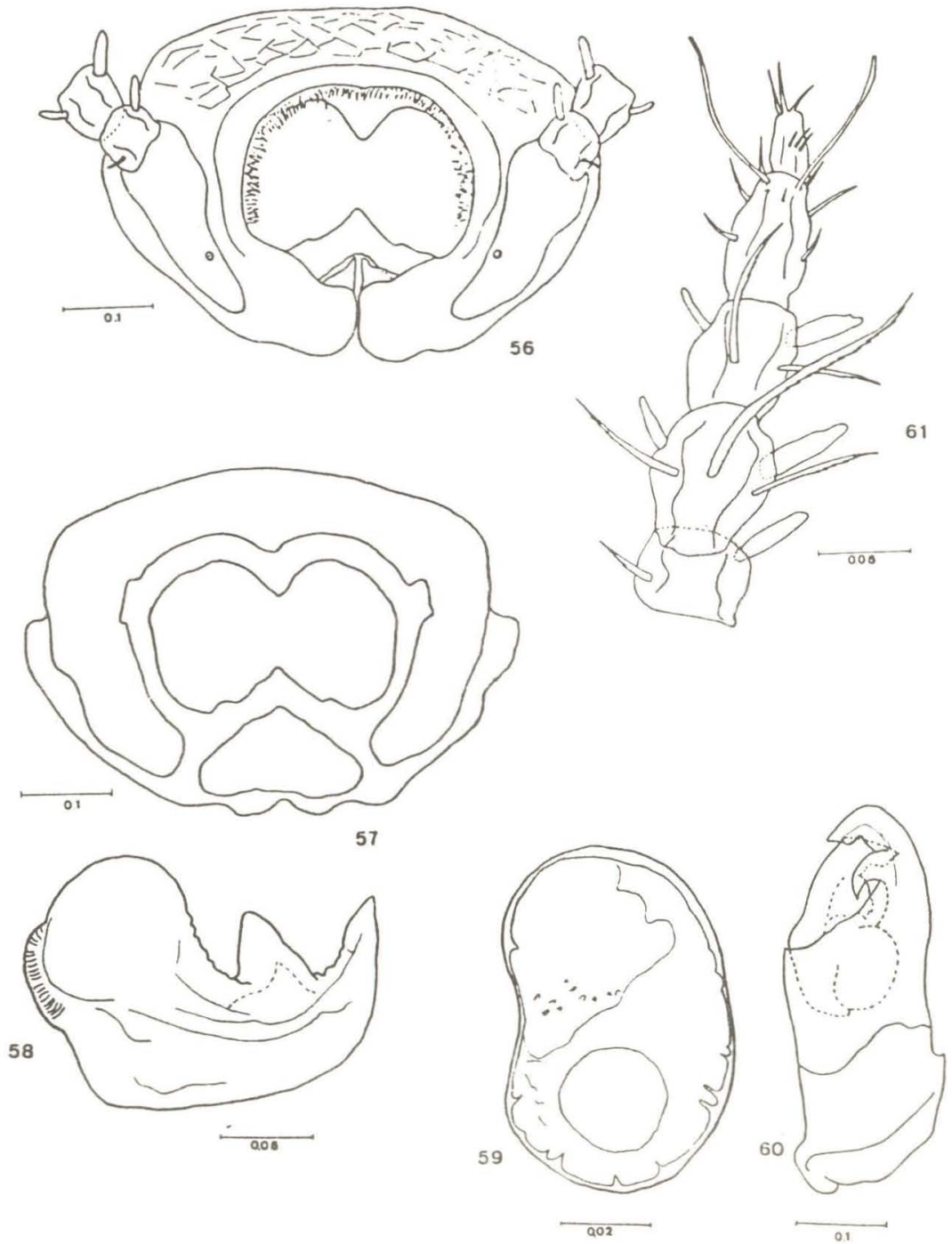

Spelaeorhynchus wenzeli sp. n. - Fêmea adulta: Fig. 56 - Gnatossoma visto de frente; Fig. 57 Gnatossoma visto por trás; Fig. 58 - Dígito móvel; Fig. 59 - Peritrema;Fig. 60 - Quelícera;Fig. 61 - Vista dorsal do palpo. Escalas em mm. 
QUADRO 1

Média, desvio paúrão e amplitude de variação das medidas consideradas nas diversas amostras de Spelaeorhynchus praecursor Neumann, 1902

BRASIL

VENEZUELA

JAMAICA

GUATEMALA

HONDURAS BRITĀNICAS

MÉXICO

Comprimento do escudo esternal

$\mathrm{N}=26$

Média $=0,267 \mathrm{~mm} \pm 0,021$

$\mathrm{N}=25$
Média $=0,286 \mathrm{~mm} \pm 0,018$

$\mathrm{N}=13$

Média $=0,286 \mathrm{~mm} \pm 0,022$

$\mathrm{N}=12$

Média $=0,290 \mathrm{~mm} \pm 0,019$

Comprimento do peritrema

\section{$\mathrm{N}=26$}

Média $=0,089 \mathrm{~mm} \pm 0,003$

Amplitude $=0.074 \mathrm{~mm} \cdot 0,106 \mathrm{~mm}$

$\mathrm{N}=25$

Média $=0,090 \mathrm{~mm} \pm 0,004$

$\mathrm{N}=13$

Média $=0,093 \mathrm{~mm} \pm 0,007$

$\mathrm{N}=12$

Média $=0,089 \mathrm{~mm} \pm 0,004$

Comprimento da quelícera

$\mathrm{N}=26$

Média $=0,435 \mathrm{~mm} \pm 0,032$

$\mathbf{N}=\mathbf{2 5}$

Média $=0,434 \mathrm{~mm} \pm 0,006$

$\mathrm{N}=12$

Média $=0,460 \mathrm{~mm} \pm 0,016$

$\mathrm{N}=11$

Média $=0,409 \mathrm{~mm} \pm 0,024$

Amplitude $=0,397 \mathrm{~mm}-0,483 \mathrm{~mm}$

Amplitude $=0,408 \mathrm{~mm}-0,462 \mathrm{~mm}$

Relação comprimento do peritrema/comprimento do escudo esternal

$\mathrm{N}=26$

Média $=0,334 \pm 0,032$

Amplitude $=0,288-0,386$

$\mathrm{N}=25$

Média $=0,314 \pm 0,025$

$\mathrm{N}=13$

Média $=0,327 \pm 0,043$

Amplitude $=0,258-0,356 \quad$ Amplitude $=0,265-0,381$

$\mathrm{N}=12$

Média $=0,307 \pm 0,23$

Amplitude $=0,268-0,349$

Relação comprimento da quelícera/comprimento do escudo esternal

$\mathrm{N}=26$

Média $=1,642 \pm 0,153$

Amplitude $=1,316-1,914$

\section{$\mathrm{N}=25$}

Média $=1,521 \pm 0,102$

$\mathrm{N}=12$

Amplitude $=1,333-1,673$

Média $=1,617 \pm 0,119$

$\mathrm{N}=11$

Média $=1,561 \pm 0,138$

Amplitude $=1,372-1,831$

Relação comprimento do peritrema/comprimento da quelícera

$\mathrm{N}=26$

Média $=0,206 \pm 0,015$

$\mathrm{N}=25$

$\mathrm{N}=12$

Média $=0,206 \pm 0,009$

Média $=0,201 \pm 0,009$

$\mathrm{N}=11$

Amplitude $=0,190 \cdot 0,224$

Amplitude $=0,179-0,235$

Amplitude $=0,1900,0,312$ 


\section{AGRADECIMENTOS}

Deixamos consignados os nossos agradecimentos ao Preparador de Museu Onézimo Ferreira Fraga pelo auxilio nos trabalhos de campo e de laboratório; ao Dr. Jorge Jim, do Departamento de Zoologia da Universidade Estadual Paulista, campus de Botucatu, São Paulo, por ter enviado interessante material colecionado em Xavantina, Mato Grosso; ao saudoso Dr. Lauro Pereira Travassos Filho, do Instituto Butantan, São Paulo, por ter colocaoo à nossa disposição material depositado na Seção de Parasitologia do Instituto Butantan e na Escola Paulista de Medicina; ao Dr. Rupert L. Wenzel, do Field Museum of Natural History, Chicago, EUA, por ter enviado valioso material depositado na coleção de sua instituição; ao Dr. Vernon J. Tipton, da Brigham Young University, Utah, EUA, por ter remetido numerosos exemplares colecionados sobre quirópteros da Venezuela; aos Drs José Jurberg, da Fundação Instituto Oswaldo Cruz, e Arnaldo Campos dos Santos Coelho, do Museu Nacional do Rio de Janeiro, pelas facilidades na obtenção da bibliografia indispensável aos nossos estudos; ao acadêmico Henrique Reigadas pelo dedicado auxilio; ao Conselho Nacional de Desenvolvimento Cientifico e Tecnológico (CNPq) pelos auxílios concedidos, sem os quais dificilmente poderíamos ter iniciado nossas pesquisas mastozoológicas.

\section{REFERÊNCIAS BIBLIOGRÄFICAS}

ARAGÃO, H. \& FONSECA, F., 1961. Notas de ixodologia. VIII. Lista e chave para os representantes da fauna ixodológica brasileira. Mem. Inst. Osw. Cruz, 59(2): 115-130, 27 ests. cols.

BAKER, E.W. \& WHARTON, G.W., 1952. An introduction to acarology. XIII + 465 pp ., 377 figs., Macmillan, New York.

BAKER, E.W., CAMIN, J.H., CUNLIFFE, F., WOLLEY, T.A. \& YUNKER, C.E., 1958. Guide to the families of mites Institute of Acarology, Contr. no 3, 231 pp., illus.

BANKS, N., 1915. The acarina or mites. A review of the group for the use of economic en tomologists. Rep. U.S. Dep. Agric., 108: 1-153, 294 figs.

BANKS, N., 1917. New mite s, mostly economic. Ent. News, 28: 193-199, 2 pl., 15 figs.

DIAS, J.A.T S., 1958. Notas ixodológicas. V. Acerca de alguns ixodídeos do Museu de Hamburgo. Mem. Mus. Zool. Univ. Coimbra, 253:1-32, 5 figs.

DUS BÄBEK, F., 1970a. New records of parasitic mites (Acarina) from Cuba and Mexico. Mitt. Zool. Mus. Berl., 46 (2): 273-276.

DUSBÁBEK, F., 1970b. On the cuban species of the genus Spelaeorhynchus (Acarina). Acarologia, $12(2): 258-261,5$ figs.

EWING, H.E., 1929. A manual of external parasites. XIV + 225 pp., Baltimore, EUA.

EWING, H.E., 1934. The suborders and superfamilies of Acarina. Proc. Helm. Soc. Wash., 1 (2): 64-65.

FAIN, A., ANASTOS, G., CAMIN, J. \& JOHNSTON, D., 1967. Notes on the genus Spelaeorhynchus Description of S. praecursor Neumann and of two new species. Acarologia 9 (3): $535-556$, 25 figs.

FONSECA, F., 1935. Notas de acareologia. XVII. Localização, freqüência, distribuição geográfica e hospedadores de Spelaeorhynchus latus Banks, 1917 (Acarina, Spelaeorhynchidae). Mem. Inst. Butantan, 9: 145-148.

FONSECA, F, 1937. Remarks of the tick "Spelae orhynchus latus" Banks. Proc. XII Int. Cong. Zool., sec. VIII : 1580-1583.

FONSECA, F., 1958. Acarologische notizen. XLII. Geruchsorgane und entwicklungsgeschihte der Mesostigmata und Spelaeorhynchidae (A cari). Mem. Inst. Butantan, 29:55-58, 1 fig.

F OX, I., 1942. The occurrence of a rare genus of ticks on bats in Puerto Rico. (Acarina, Spelaeorhynchidae). J. Agr. Univ. P.R., 26(4): 95-97.

KRANTZ, G.W., 1975. A manual of Acarology. 335 pp., illus., Oregon St. Univ., EUA.

LOMBARDINI, G., 1938. Chiave a nalitica ai sottordini alle superfamiglie ed alle famiglie degli Acari. Redia, 24: 199-217, 28 figs. 
Vol. 7(1-2), 1990

MACHADO-ALLISON, C.E., 1967. Sobre algunos ectoparăsitos de mamíferos de la Biota Amazonica. Atas do Simpósio sobre a Biota Amazônica, 5 (Zool.): 365-372.

NEUMANN, L.G., 1902. Spelaeorhynchus praecursor n.g., n.sp. nouvel acarien parasite. Arch. Parasitol., 5: 31-37, 9 figs.

NEUMANN, L.G., 1906. Note sur S pelaeorhynchus praecursor Nn. Arch. Parasitol., 110: 220.

NEUMANN, L.G., 1911. Ixodidae. Tierreich, A carina, 26:1-169.

OUDEMANS, A.C., 1902. In Verslag van de vijfen-dertigste Wintervergadering der Ned. Ent. Ver. Tijdschr. Ent., $45: 50-64$.

RADFORD, C.D., 1950a. The mites (Acarina) parasitic on mamals, birds and reptiles. Parasitology, $40(3,4): 366-394$.

RADFORD, C.D., 1950b. Systematic check list of mite genera and type species. Union Int. Sci. Biol., ser. C (sec. Ent.), 1:1-232.

SINGER, G. 1967. A comparison between different mounting techniques commonly employed in Acarology. Acarologia, 9 (3): 475-484.

TABOADA, GS., 1965. Lista de los parásitos hallados en murciélagos cubanos. Poeyana, ser. A, 12: $1-14$.

TAMSITT, J.R. \& FOX, I., 1970. Records of bat ectoparasites from the Caribbean region (Siphonaptera, A carina, Diptera). Can. J. Zool., 48 (5): 1093-1097.

TAMSITT, J.R. \& VALDIVIESO, D., 1970. Observations on bats and their ectoparasites in A tropical rain forest. XIV + 1640 pp., U.S. A tomic Energy Commission, Washington.

VIGUERAS, I.P., 1956. Los ixódidos y culícidos de Cuba, su historia natural y médica. 579 pp., 107 pl., 338 figs., Univ. La Habana, Cuba.

VITZTHUM, H.G., 1931, 9. Ordnung der Arachnida: Acari, Milben in Handbuch der Zoologie, Kuekenthal, 3 (2): 2a. parte, 1-160, 161 figs.

VITZTHUM, H.G., 1940-1942. Acarina in Bronn's Klassen und Ordnungen des Tierreichs, 5 (4), parte 5: 1-1011, illus.

ZUMPT, F., 1951, IX. Vorstudie zu einer Revision der gattung Rhipicephalus Koch. Phylogenie der Zecken und "natürliches Sustem". Z. Parasitenk., 15:87-101.

ZUMPT, F., AUDY, J.R., GAUD, J., LAWRENCE, R.F., THEILER, G., TILL, W.M. \& VERCAMMEN-GRANDJEAN, G.P., 1961. The arthropod parasites of vertebrates in Africa south of the Sahara (Ethiopian region) I. (Chelicerata). Publ. South Afr. Inst. Med. Res., 9 (1): $1.457,247$ figs. 